\title{
Growing Up Is Hard to Do: An Empirical Evaluation of Maturation and Desistance
}

\author{
Michael Rocque ${ }^{1}$ - Chad Posick ${ }^{2}$ - Helene R. White ${ }^{3}$
}

Received: 5 August 2015 / Revised: 19 October 2015 / Accepted: 27 October 2015 /

Published online: 13 November 2015

(C) Springer International Publishing AG 2015

\begin{abstract}
Purpose With an increase in longitudinal datasets and analyses, scholars have made theoretical advances toward understanding desistance using biological, social, and psychological factors. In an effort to integrate the theoretical views on desistance, some scholars have argued that each of these views represents a piece of adult maturation. Yet to date, research has not empirically examined an integrated perspective. The purpose of this study is to conduct an exploratory examination of various "domains" of maturation to determine whether they explain desistance from crime separately and as a whole.

Methods Using the Rutgers Health and Human Development Project, a longitudinal study spanning ages 12-31, we develop exploratory measures of maturation in five domains: (1) adult social roles, (2) identity/cognitive, (3) psychosocial, (4) civic, and (5) neurocognitive. We then utilize growth curve models to examine the relationship between these domains and crime over time.

Results Although each of the domains is associated with crime at the bivariate level, only three (i.e., psychosocial, identity/cognitive transformation, and adult social role) remain significant in the growth curve models (only two in within-individual analyses). In addition, a combined measure of maturation is related to crime, indicating that greater maturation through emerging adulthood has a negative effect on criminal behavior and is, therefore, a factor influencing desistance.

Conclusions Maturation emerges as a promising approach to integrating the multiple theoretical views that characterize the literature on desistance from crime. Further
\end{abstract}

Michael Rocque

mrocque@bates.edu

1 Department of Sociology, Bates College, 265 Pettengill Hall, Lewiston, ME 04240, USA

2 Department of Criminal Justice and Criminology, Georgia Southern University, 1332 Southern Drive, PO BOX 8105, Statesboro, GA 30458, USA

3 Center of Alcohol Studies, Rutgers University, 607 Allison Road, Piscataway, NJ 08854-8001, USA 
research should develop additional domains and determine the best approach for measurement.

Keywords Age-Crime Curve - Desistance - Growth Curve Modeling · Maturation

\section{Introduction}

Criminologists generally support the contention that there is a rise in problem behavior during adolescence and early adulthood followed by a decline in offending, known as the "age-crime curve" $[42,77,89]$. Nevertheless, researchers continue to debate the mechanisms that account for this decline. Some criminologists claim that no social variables can explain the age-crime curve and that desistance is a biological phenomenon (e.g., [36, 42]). In contrast, other criminologists have suggested that it is due to sociological factors, such as changes in social relationships (e.g., [7, 51, 81, 83]) or psychological factors, such as changing identity or "personal narrative" [10, 30, 31, 57, 67].

At the same time, research outside of criminology has discovered that changes in brain maturation (and other neuropsychological mechanisms) may lead to reductions in risk taking and antisocial behavior throughout adolescence into early adulthood [15, 29, 35, 91]. Sweeten, Piquero, and Steinberg [92] argue that the age-crime curve can be explained by a host of psychological (e.g., impulse control, moral disengagement) and social (social learning) variables (see also [23]). Given the plethora of empirically supported theoretical perspectives, it appears that desistance can best be understood by examining development over time in a holistic sense, rather than isolating biological, social, or psychological factors as extant explanations appear to do.

A recent theoretical integration was proposed by Rocque [79], who argues that "maturation" can account for desistance in a more effective manner than piecemeal theories that currently exist in the literature. The term maturation in this perspective is derived from the work of the Gluecks ([32] (1966); [33]) and not meant to connote a mechanistic, law-like process that naturally happens. Instead, Rocque's [79] view is that maturation is multi-faceted, incorporating social, psychological, and biological changes. These changes happen (or do not happen) at different times/ages for different people. That said, understanding what maturation is composed of may help practitioners "force the plant" of maturation, thereby encouraging desistance from crime ([32] (1966), p. 205).

The maturation perspective views strains of extant desistance research as identifying "domains" of adult maturation; that is, what it means to be an adult in the twenty-first century. Rocque [79] suggests that the domains of maturation, which include social role, psychosocial, identity, civic, and cognitive, are additive in their effects on desistance. Prior et al. [75] made a similar argument regarding the definition of maturation and its relation to crime. To date, research has not empirically evaluated this theoretical perspective. Thus, the purpose of the present study is to attempt to measure and analyze maturation as defined by Rocque [79] and Prior et al. [75] and examine its relationship to crime over the life course using longitudinal data from individuals followed from age 12 to 30/31. Our overall goal is to show whether maturation domains can be measured empirically, and whether those constructions 
have the anticipated effects on crime. In other words, our study is an exploratory analysis of separate domains of maturation, as well as a combined, overall maturation measure. We examine (1) how the domains of maturation change over time and (2) how the changes in domains are related to changes in crime using multi-level growth curve models. In doing so, we answer the call by DeLisi and Piquero [18] for more research on dimensions and theory related to criminal careers.

\section{Desistance From Crime}

Since researchers began examining the age-structure of criminal behavior, scholars have recognized that offending tends to peak in early adulthood and decline thereafter. In the mid-nineteenth century, Adolphe Quetelet described what has now come to be known as the age-crime curve [74]. By and large, across time and datasets, researchers have noted that criminal behavior increases through adolescence, peaking between ages 18 and 26, and then declines thereafter. The process of gradual decline in both frequency and seriousness of offending has been called desistance by researchers, eventually ending with termination of crime [50]. Research has identified this desistance phenomenon in general community samples $[27,60]$ though scholars have focused on samples of serious offenders [51,71].

With the ascent of the life course/developmental field of study in criminology, research on desistance from crime has increased dramatically, with several prominent explanations for desistance from crime having emerged recently. As Paternoster and Bushway [67] note, "[t]heorizing and research about desistance from crime is one of the most exciting, vibrant, and dynamic areas in criminology today." To date, these theoretical perspectives have advanced our understanding of crime over the life course, but little adjudication has occurred with respect to whether particular approaches are more useful than others. In fact, theoretical competition [43] is rare in the desistance literature, with few exceptions $[31,51,53]$. One reason for this state of affairs may be that each individual desistance theory contains a kernel of the desistance story, rather than each representing comprehensive competing claims. Each theory or perspective is seemingly incomplete and unable to fully account for the actual experience of offenders. In that sense, rather than competing accounts, the various theoretical perspectives may represent pieces of a larger puzzle that can help illuminate the desistance process. This is the guiding logic behind the Rocque [79] maturation model, which is described in the following section.

\section{The Maturation Perspective on Desistance}

Maturation has long been viewed as a cause of changes in behavior. Sheldon and Eleanor Glueck wrote of maturation as a reason their offender samples stopped committing crimes later in life ([32] (1966); [33]). Rocque [79] describes the issues with the Gluecks' work, including the lack of specification concerning what maturation entails - a limitation that the Gluecks themselves acknowledged. In a sense, maturation is a term that has much lay, but little academic meaning.

A recent report produced by the University of Birmingham [75] argues that maturation levels should be taken into account when deciding how to address 
juvenile offending. The report and the literature review [75] both suggest that maturation is a multi-faceted phenomenon, involving physical, emotional, social, and cognitive factors. Prior et al. [75], much like Rocque [79], rely on a number of related literatures to argue that maturation is comprised of distinct domains. Rather than seeking to clarify what maturation means, Prior et al. [75] instead discuss maturation in terms of neurological and psychological factors; thus, they show how it is relevant to criminology. Recent research has demonstrated the importance of taking external (social) and internal (cognitive) factors into account to explain recidivism, which is clearly related to desistance [54]. Thus, the plethora of theoretical developments with respect to desistance appear to map well onto different theoretical domains of maturation.

While both Prior et al. [75] and Rocque [79] offer substantial advancements in the understanding of maturation and crime, Rocque [79] goes a bit further by seeking to define what maturation offers criminology and how it can be operationalized for empirical investigation. In doing so, he identifies five key domains of maturation. We rely on Rocque's [79] model, which draws on criminological and related literatures and is specific in its definitional and operational approach. In the following section, we briefly review the five domains identified by Rocque and the literatures on which they are based.

\section{Adult Social Roles and Maturation}

The first "domain" of maturation is labeled Adult Social Role maturation. This domain draws on Sampson and Laub's [81] age-graded theory of informal social control, which is perhaps the most well-known theory of age and crime (which is more accurately a life course theoretical perspective). Resurrecting the Gluecks' [34] Unraveling Juvenile Delinquency data, and addressing shortcomings with the original analysis, Sampson and Laub develop a theory to account for both juvenile delinquency and subsequent desistance in adulthood. Drawing on Hirschi's [41] social control theory, Sampson and Laub argue, and then demonstrate, that reductions in offending can be accounted for by involvement in social institutions such as marriage, employment, and the military. Subsequent research has supported the relationship of marriage and jobs to a decrease in crime (see [7, 16, 45, 52, 82]). In addition, some research has shown that the birth of children may act as a turning point away from crime (see [81, 83, 106]). While marriage had certain symbolic value during the time that the Glueck men were coming of age, today, marriage is being delayed and cohabitation may have a similar, though lesser, anticriminogenic effect (see [28]).

The adult social role perspective is represented as only one domain in the maturation perspective, however. Research has questioned whether adult social roles have the same effect for racial minorities and females [20, 31], and whether social roles matter absent of changes in identity [53]. Thus, the adult social role maturation domain, while important, is but one component in understanding maturation overall. We do believe that social roles are useful indicators of some degree of maturation though, as scholars have long recognized transitions through life stages as "adult status markers" [21, 88]. 


\section{Identity and Cognitive Transformation Maturation}

The next domain of maturation draws on the work of Maruna [57], [30, 31]) and Paternoster and Bushway [67]. This theoretical perspective is more "subjective" than social role theories. That is, rather than attributing desistance to external factors, or random luck as Sampson and Laub [81] do by suggesting that desistance happens largely by "default," identity theories assume that the offender does not desist until he or she comes to see his/herself differently and views criminal behavior as unattractive. Maruna [57], analyzing interviews with offenders in Liverpool, UK, finds that those who claim to be desisting or "making good" no longer see themselves as deviant and actively try to reinterpret their past behavior as consistent with their prosocial self. The exoffenders also have a strong desire to "give back" to their community, thus viewing the purpose of their lives differently than active offenders (see also [26]). Similarly, Giordano et al. [31], after analyzing interviews with a sample of men and women, argue that changes in perceptions of crime, as well as views of the self, facilitated desistance far better than social roles such as marriage or jobs. That is, "cognitive transformations" in evaluation of criminal behavior and one's identity occur, which facilitate desistance from crime. It is important to note, though, that for these cognitive transformations to have an effect on behavior, exposure to "hooks" for change or prosocial opportunities must be present. Finally, Paternoster and Bushway [67] offer a more explicit identity theory in which desistance is said to be caused not by social relationships but by a shock that leads offenders to question their current lives and decide to change who they are. Adolescence is the time when individuals are changing their cognitive perception of "what is" to "what might be," informing their sense of personal identity (Piaget and Play 1962). In that sense, it is similar to Shover's [84] work, which shows that offenders come to question the path they are on when they are confronted with some harsh reality, such as imprisonment. The key element linking these theories is that is changes in how one views oneself (e.g., from a criminal to a good person) that leads to change in behavior.

Thus far, research on identity and cognitive transformations has supported the identity perspective but has been mostly limited to qualitative work [31, 49, 57, $64,65]$, and thus has not been able to assess changes in identity over time. Some recent research has begun to explore quantitative measures of identity, finding that changes in views of the self do, in fact, correlate prospectively with decreases in crime [78]. However, identity theories, while seemingly representing a large part of the desistance puzzle, may not be sufficient to explain the phenomenon ([32] (1966)). Giordano and colleagues [31] recognize this and suggest that identity change may lead to desistance with the help of "scaffolds" such as marriage and employment. Lebel et al. [53] find that subjective factors (such as identity) affect desistance in part through their influence on objective, social control factors. They argue that desistance must be seen as a result not just of either objective or subjective factors but an interaction between the two. In other words, both social roles and changes in identity (whatever the relation between the two) appear important in explaining desistance. 


\section{Psychological/Psychosocial}

One body of work which has not featured prominently in the criminological literature on desistance explores the influence of psychological factors on the cessation of criminal behavior. Rocque's [79] maturation model includes these factors as a separate domain of maturation and points to the personality and psychosocial maturation literatures as especially pertinent. Blonigen [8] offers a theory of desistance, which draws on psychological research showing that personality factors positively related to crime tend to decrease, whereas those factors negatively related to crime tend to increase over the life course. For example, research has shown that impulsivity, risktaking, and sensation-seeking peak in late adolescence, and decline thereafter, while traits such as agreeableness and conscientiousness increase through adolescence and early adulthood coinciding with the age-crime curve [9, 91]. In other words, criminogenic risk factors appear to cluster in adolescence but become fewer or less prominent in the early adult years, while traits that are negatively correlated with antisocial behavior increase through the first stages of adulthood.

The concept of psychosocial maturation is also relevant for this domain (see [75]). Described by Cauffman and Steinberg [12], psychosocial maturation incorporates three dimensions: (1) temperance, or impulsivity, and aggression control; (2) responsibility, or the tendency to take ownership for ones actions and to not have to rely on others (e.g., the view that life outcomes are due to one's own doing); and (3) perspective, which refers to being able to see the larger picture and not be self-focused. Perspective also represents the ability to think about the future rather than the "here and now." These dimensions all lead to what Cauffman and Steinberg call "maturity of judgment." Thus, psychosocial maturity is an indicator of improved decision-making that develops in adulthood.

Research has tended to show that psychosocial maturation does increase over time and that it is negatively related to crime over the life course [12, 13, 59]. In addition, disruptions in normal adolescent development may also lead to stunted psychosocial maturation (see [19]). Psychosocial maturation is therefore a potentially important developmental psychological factor that has much relevance to desistance from crime.

\section{Civic/Communal Maturation}

Social science research has long recognized the importance of community, civic engagement, and social capital to a feeling of belonging and emotional ties [40, 76]. According to Balsano [4], "Civic engagement represents an important vehicle in promoting positive development among youth" (p. 188). With respect to development over time, civic engagement appears to be an important part of growing up and transitioning to adulthood [25]. Civic engagement and citizenship tend to increase in adulthood when individuals begin to think less of themselves and more of what they can do for others, a notion that Maruna [57] refers to as "generativity." Generativity leads to more active engagement and citizenship activities, which provide a stake in the community and thus conformity [4]. Theoretically, those individuals who come to have a greater stake in prosocial community will be less likely to continue to be deviant over time. Recent research has found that community reintegration efforts may be a key part of helping offenders desist from crime. Fox [26], using data from the Circles of Support 
and Accountability program, found that offenders who received assistance and moral support in rejoining the community may have lower rates of desistance in part due to instilling feelings of mutual obligation with community members. Weaver and McNeill [102] offer further evidence of the importance of restorative efforts and social networks in encouraging desistance.

Research in criminology has indicated that civic engagement and citizenship are inversely related to crime and delinquency [96, 97]. Uggen, Manza, and Behrens [98] argue that civic engagement and citizenship represent an important part of the desistance process, helping to build one's "prosocial identity" (p. 261). Thus, felon disenfranchisement policies may actually interfere with the process of desistance (see also $[55,56,99])$.

In terms of normative development, Rocque's [79] model includes civic engagement activities, such as belonging to clubs and organizations, and volunteer work. Voting and participation in local government would also apply here. The developmental process captured by these activities is that of the growth of the communal identity and of viewing others as important rather than being self-centered. Prior et al. [75] discuss generativity and community engagement as part of psychosocial maturation.

\section{Neurocognitive Maturation}

Rocque [79] and Prior et al. [75] draw on neurological research that suggests the brain is not fully developed until individuals are in their early to mid-20s [35, 38, 97, 100]. This research has important implications for behavior and responsibility, as the areas thought to be underdeveloped in adolescence are related to risk taking and impulsivity [91]. Briefly, through adolescence and into "emerging adulthood," there appears to be a decrease in gray matter and an increase in white matter, thought to improve neural connectivity and information transmission [29, 35, 86]. These changes lead to improved cognitive functioning and more responsible behavior [87, 100].

Thus, the final domain of maturation in Rocque's model is cognitive or neurological maturation. While this research has influenced sentencing policy on a federal scale (see [73]), leading the US Supreme Court to ban life in prison without parole and the death penalty for juveniles, it has had a minimal impact on life course criminological work (see [15]). As such, it is perhaps the least "theorized" of the major domains of maturation described in this study. An ideal way to measure neurological or cognitive maturation would be to utilize technology that can assess the structure of the brain. However, absent these data, as Rocque [79] suggests, this domain should be indexed by proxies such as neuropsychological exams.

\section{Current study}

The maturation perspective recognizes that each of the above-mentioned areas (social role, civic, psychosocial, identity, and neurocognitive) is important with respect to desistance, but each, on its own, has limitations. While maturation appears to be linked to crime and desistance over the life course, and kernels of the concept can be found across diverse literatures, there has yet to be a comprehensive empirical examination of a complete maturation perspective. In general, these theories - or pieces of the theories-are tested separately and the theorists have suggested that certain factors (e.g., 
social roles) are more important than others in understanding desistance (see [67]). Integrated, or comprehensive perspectives, such as the maturation perspective, have rarely been put forth and/or tested [23]. As Rocque [79] points out, it is difficult to test a comprehensive model because most datasets do not contain all of the measures needed.

The purpose of this paper is to provide a preliminary measurement of the five domains of maturation and to examine their relationship to crime over the ife course. Thus, we test separate models for each domain as a way to determine their independent influence on crime, as well as an overall combined measure that allows us to examine the effect of maturation as a whole. Our measures are not meant to be the final word on the subject but offer a first step toward operationalizing maturation and empirically analyzing the concept over time. The measures are not treated as latent constructs or psychometric tools but rather objective, empirical indicators to serve as a way to examine maturation and crime. The study will therefore be able to show (a) how maturation may be measured and (b) whether a comprehensive measure of maturation is a useful way to understand desistance from crime, as opposed to viewing theories as separate and competing (and therefore incomplete). The analysis will contribute to a further understanding of how well current theory accounts for criminal careers. DeLisi and Piquero [18] argue that more research is needed to determine how well theories can provide a "comprehensive" understanding of criminal career elements, such as desistance.

\section{Methods}

\section{Design and Participants}

To examine how the domains of maturation change over time and how the domains are related to crime, we use data from the Rutgers Health and Human Development Project (HHDP; [66]). The data include measures of physiological, cognitive, social, emotional, and activity-related topics. Thus, the HHDP is well suited to address the domains that Rocque [79] proposed. This study, initiated in 1979, followed three cohorts of adolescents throughout their teen and early adult years into their early 30 s. To obtain the sample, researchers used random phone calls to homes in the state of New Jersey in USA (all counties except for five that were geographically far from the test site were included). Youth who fit the eligibility criteria (no physical or mental disabilities, English speaking, and age) were recruited to take part in the study. The final sample recruited at T1 included 1380 subjects, split relatively evenly by sex (698 males, 682 females). The subjects enrolled in the study at T1 were mostly white (89\%); about half Catholic (30\% Protestant, $9 \%$ Jewish, $11 \%$ other); and nearly all (90\%) lived with their birth parents. The subjects' families in terms of socioeconomic status were primarily working to middle class (median income at T1: between US\$20,000 and US $\$ 29,000)$. The project researchers concluded that overall, the sample succeeded in faithfully representing white middle-class and working-class youth in New Jersey at the beginning stages of the study [39].

At time 1 (T1), the first cohort was aged 18 (they were born in 1961-1963), the second was aged 15 (born 1964-1966), and the third was aged 12 (born 1967-1969). In this study, we focus on the youngest cohort, which has the most waves of data available 
and spans from early adolescence into young adulthood (230 males and 217 females). After the initial data collection (at age 12), this cohort was interviewed at age 15 (time 2, T2); age 18 (time 3, T3); age 25 (time 4, T4); and age 30/31 (time 5, T5). The study had a low attrition rate, with more than $90 \%$ of the original sample interviewed at T2T4 and $84 \%$ of the original sample interviewed at T5. Each wave of data included interviews with trained researchers, completion of self-report questionnaires, and laboratory tests. Each data collection time period took place over roughly $5 \mathrm{~h}$. The study was approved by the Rutgers University Institutional Review Board. Additional details on the HHDP study can be found in Pandina et al. [66] and White, Pandina, and LaGrange [104].

\section{Data and Measures}

Table 1 displays descriptive information for the main variables of interest at each time point. We believe that our constructions, while not perfect, are faithful to the original vision of previous theoretical foundations developed by others. We provide a brief discussion on domain construction in the following section. See the Appendix for full item information at each time period.

The dependent variable for this study is a variety score containing nine items including the following: (1) avoiding payment, (2) breaking and entering, (3) using a weapon in a fight, (4) auto theft, (5) armed robbery, (6) assault, (7) vandalism, (8) petty theft (of goods worth less than US\$50), and (9) major theft (over US\$50). At T4 and T5, the item "used a weapon in a fight" was no longer available. Therefore, we follow previous researchers and use "gang fights" in its place [105]. At each period, respondents were asked how many times they engaged in the offenses during the last 3 years. Descriptive statistics for the variety score are presented in Table 1. As is shown, crime increases over time until age 18 when it starts to decline.

Six covariates are included in the following models. Race and sex are coded with nonwhite (Asian, Black, and Other race) and males coded as 1 . As can be seen in Table 1 , only $9 \%$ of the sample is nonwhite and just over $50 \%$ of the sample is male. Socioeconomic status (SES) is based on parental education and occupational status at T1 [44]. The average score is 52 out of a possible 77 indicating predominantly a working and middle class sample, which mirrored the average SES for New Jersey at the time.

Grades are measured by asking respondents what their grades were on their last report card. This measure ranges from 1 to 4 at T1 and 1 to 5 at T2-T3. ${ }^{1}$ Here, lower scores represent higher overall grades (e.g., 1=A and 5=F). Based on Hirschi [41], parental bonding is measured at T1-T3 using a scale representing the sum of five items asking the respondents how they feel about their parents (e.g., "how much do you respect your parents") with higher scores indicating a greater level of attachment.

\footnotetext{
${ }^{1}$ Note that at T1, there were three "waves" of data collection, and the response categories differed between wave I and waves II-III. The response categories at wave I were $1=\mathrm{A}, 2=\mathrm{B}, 3=\mathrm{C}, 4=\mathrm{D}$, and $5=\mathrm{F}$. During waves II and III, they ranged as $1=\mathrm{A}, 2=$ between $\mathrm{A}$ and $\mathrm{B}, 3=\mathrm{B}, 4=$ between $\mathrm{B}$ and $\mathrm{C}, 5=\mathrm{C}, 6=$ between $\mathrm{C}$ and $\mathrm{D}, 7=\mathrm{D}$, and $8=\mathrm{F}$. To make the response categories equivalent, for waves II and III, categories were recoded such that 1 and $2=\mathrm{A}, 3$ and $4=\mathrm{B}, 5$ and $6=\mathrm{C}, 7=\mathrm{D}$, and $8=\mathrm{F}$. This was also done at $\mathrm{T} 2$ and $\mathrm{T} 3$, in which the grading coding was similar to waves II and III of T1. Thus, for all time periods, the range of possible grades will be 1 (A) to $5(\mathrm{~F})$.
} 
Finally, friends' deviance is a measure of the level of delinquency of the respondent's peers using a battery of 20 questions. Each response was coded on a Likert scale ranging from none to all. Because of different metrics at different time periods, the friends' deviance measures (which were originally summed) were standardized to create the scales used in this study so that they all had a mean of 0 and a standard deviation of 1 . See Table 1 for more variable information.

\section{Domain Construction}

As described in the following section, each domain varies with respect to the number of items and coding of items. Thus, a simple average of each item/scale that was identified to represent the domain would not be adequate. To address this, we employ a variant of percentage of maximum possible score methods (POMP, [14]), which is a preferred and intuitive way of calculating aggregate scores. For this study, we determined the highest score possible on each scale/ item in each domain, then summed across those items/scales and divided by the highest possible score a respondent could receive and then multiplied by 100 . This places the scale on a theoretical metric of lower bound to $100(\%)$, with higher scores indicating greater levels of maturation, ${ }^{2}$ while also allowing us to explore growth over time as the metric is equivalent across time periods. In cases in which substantial missing data existed on one or more items/scales comprising a domain, we constructed the domain requiring at least half of the items/scales to be valid. We also created a "total" maturation measure, which is the average of all domains at each time point, as well as an "overall" maturation measure which provides the average maturation score for each individual (one score per individual).

We note that psychometric analyses (e.g., Cronbach's alpha), which are traditionally computed for scales are not conducted for the total domain scores for a variety of reasons, not the least of which is these are exploratory, initial measures. ${ }^{3}$ Primarily, however, we view the above-mentioned constructions as "indexes" rather than scales. That is, they reflect formative measures in which the latent trait is caused by the indicators. In scale formation, classical test theory is relevant, and the indicators are thought to be "reflective" or caused by the latent trait (see [17]). In this scenario, there is good reason to assume the indicators are intercorrelated and, in fact, if they are not, that the scale is not reflective of the trait. In index creation, there is no reason to assume the indicators or measures are a priori intercorrelated. For example, it is clear that more social roles (e.g., marriage, job, parenthood) indicate a higher level of adult social bonds, but there is no reason to assume that people who have jobs also have children or are married. Thus, our measures of maturation are viewed as formative indexes indicative of maturation, rather than being caused by maturation. Next, we describe the composition of each specific maturation domain.

\footnotetext{
${ }^{2}$ Some domains included only items/scales which had a lower bound of 1 so a 0 on the domain was not possible.

${ }^{3}$ Note some of the constructed measures within domains do use reliability analyses since these were often meant to represent scales (e.g., cognitive structure, a measure used in the psychosocial maturation domain, was created by PRF researchers).
} 


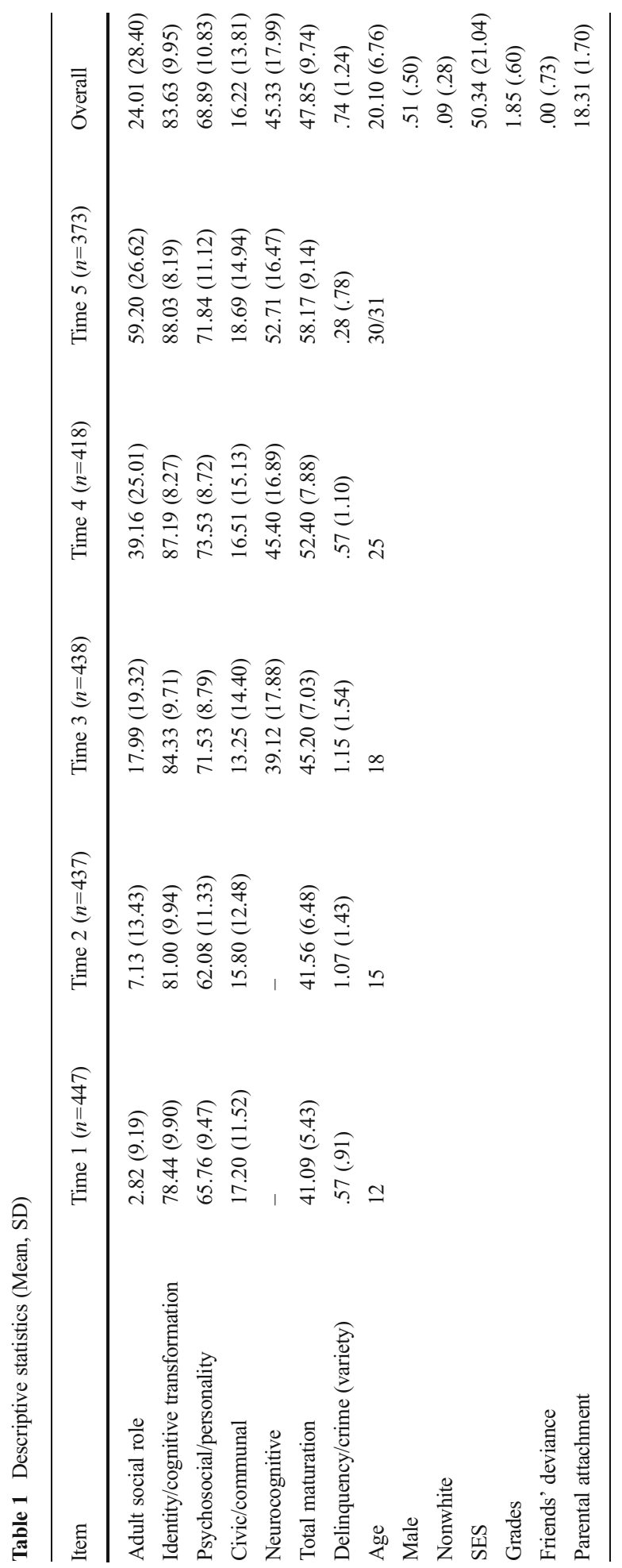




\section{Adult Social Role Maturation}

The measures of social maturation involve mainly adult social roles (e.g., romantic relationships, work/employment, and education). While some researchers have considered adult social relationships to be a result or consequence of maturation (e.g., [22]), there is sufficient evidence that such relationships are a part of the transition to adulthood, which implies they are a part of the maturation process. To capture adult social role maturation, we include full- and part-time work, romantic relationships (e.g., married or cohabitating), whether the respondent had children, whether the respondent graduated high school or attended college and, importantly, work and relationship attachment scales. Note the presence and number of items/scales that comprise the full adult social role measure vary by time period. In addition, because at certain ages particular items or scales would be more appropriate than at others (e.g., we only include full-time work at T3-T5, but include part-time work at T1 and T2), we make slight adjustments to ensure the measure is meaningful.

\section{Identity/Cognitive Transformation Maturation}

A battery of four items, identical across all time periods, is used to measure identity. These items ask the individuals to rate themselves on a scale of 1 to 5, with respect to whether they are "good," "mean," "dishonest," and/or "delinquent/troublemakers." All items were coded such that higher scores indicate a more prosocial orientation. For example, those scoring high on this measure would see themselves as "not" mean or dishonest, but rather good. These items did not form adequate scales according to intercorrelation and factor analyses and thus are kept as separate items.

Two measures are used to measure cognitive transformations, available at T4 and T5 only. The first represents views toward criminal acts. It is comprised of six items asking how much guilt or remorse the individual would feel if they did certain deviant acts. Analyses indicated that five of the items formed a single unidimensional measure, which we call "view crime." Second, a battery of 10 items was available asking about honesty and how important it is to do things without cheating or lying. Items were originally scored $1-5$, with a 5 representing complete disagreement. This scale was created by taking the average of the items such that higher scores indicate a more prosocial orientation, in conjunction with the other identity/cognitive transformation measures.

\section{Psychosocial Maturation/Personality}

Because Cauffman and Steinberg's [12] conceptualization has been shown to be related to crime over time (see [59]), the measurement of psychosocial maturation relies on their work (focusing on temperance, responsibility, and perspective). In Cauffman and Steinberg's [12] scheme, responsibility refers to the ability to think for oneself, to take care of oneself, and relative independence. This construct includes self-reliance, selfesteem, and independence. To measure responsibility, several items/scales are used. These include items indicating how confident or responsible the respondent feels they are; scales from personality questionnaires measuring self-sufficiency (16PF Q2 factor; [11]), and a constructed scale indicating how much the respondents felt their lives were due to luck (at T3-T5). 
Temperance refers to the ability to control impulses and avoid aggressive behavior. The measurement of this component of psychosocial maturation focuses on impulsivity, which is measured with the Personality Research Form (PRF) [47] scale for impulsivity or self-control at T1 and T2 and the 16PF self-control scale at T3-T5. In addition, at T4 and T5 the HHDP included several items that represented thoughtful decision-making and attention to detail, similar to what Paternoster and Pogarsky [62] call "thoughtfully reflective decision-making." Analyses indicated that five of these items formed a psychometrically adequate scale at both times. This scale represents the tendency to think things through before making a decision and pay attention when engaging in activities (the latter is a vital factor in the ability to think about all alternatives in making decisions).

Perspective refers to the ability to think about and plan for the future, as well as the tendency to think about others. In many ways, this component of psychosocial maturation overlaps with the personality trait of agreeableness, which Blonigen [8] argues increases over the life course. To measure perspective, a battery of four items from T1 to T5 is used which asks the respondents to describe themselves (e.g., "helpful," "understanding," "aware of others' feelings," and "kind"). These items were averaged into a scale we call "Agreeableness." This measure is conceptually related to the "Consideration of Others" subscale, which is one of the measures used by Cauffman and Steinberg [12] to represent perspective. Finally, the PRF includes a subscale entitled "cognitive structure," which represents the tendency to desire clear plans and a lack of ambiguity about the future. The cognitive structure scale of the PRF includes 12 items such as "I very seldom make careful plans" and "I don't like to go into a situation without knowing what I can expect from it." ${ }^{\prime 4}$ All items were recoded such that high scores indicate more cognitive structure and summed.

\section{Civic/Communal Maturation}

Civic maturation is measured by a series of items that represent whether the respondent was involved in a variety of "in school" and "out of school" clubs and activities. School activities include organizations such as service, athletics, and school government. Out of school activities include such organizations as scouting, service, religious, and social groups. School activities were only relevant for those in high school or lower, and are not available after T3. These items were combined to create a sum of activities or organizations the individual engaged in at each time (both in school and out of school). ${ }^{5}$

Another item, which was only available at T4 and T5, measures satisfaction with civic activities. This item asked respondents how happy they were with their civic or church related duties. "Satisfaction with civic activities' ranged from 1 to 5 originally, and was trichotomized such that if the score was "not-applicable," they received a 0 , if the score was 1,2 , or 3 (very dissatisfied through neutral), they received a 1 , and if the score was 4 or 5 (somewhat satisfied and very satisfied) they received a 2 .

\footnotetext{
$\overline{{ }^{4} \text { This scale was available at } \mathrm{T} 1}, \mathrm{~T} 2$, and $\mathrm{T} 5$. It was not included at $\mathrm{T} 5$ due to insufficient psychometric properties $(\alpha=.60)$. All other subscales in each maturation domain had $\alpha>$ than .60 and at least .64. With cognitive structure, the T5 psychosocial maturation decreases slightly.

${ }^{5}$ At T3, the in school activities item had missing data for those not in school, thus the civic maturation score at this time was calculated as long as the respondent had at least one of the two valid items. This ensures that the majority of the sample has a score for civic maturation.
} 


\section{Neurological/Cognitive Maturation}

Because MRI data were not available in the HHDP, neuropsychological tests are used as a proxy for brain maturation as researchers have done in other longitudinal datasets (see for example, [90]). In the HHDP, neuropsychological tests were given starting at T3. These tests were designed to measure intelligence and cognitive impairment. These include the following: Halstead Subtests: (1) Trail-making A and B, which requires the subject to connect circles in order. B test includes "task-switching." The trail-making tests measure visio-spatial aptitude. One of their purposes is to identify brain deficits, but they also measure processing and executive functioning (see [94]); (2) The Booklet Category Test measures executive ability. The test involves the ability to find solutions to problems and adapting to new situations [105]. WAIS-R Subtests: (1) Digit Span is an intelligence test, which tests memory functioning and is a measure of verbal intelligence; (2) The Block Design tests visual and motor functioning. The test consists of arranging same colored blocks in a pattern; 3) The Digit Symbol is a test of performance IQ, which measures brain deficits or dementia. Subjects match symbols to numbers as quickly as possible (see [48]). The Shipley Institute of Living (SIL) is an intelligence test that includes two subcomponents: (1) a vocabulary test consisting of measures of vocabulary proficiency and (2) an abstraction test, which requires the use of logic. These tests measure general intelligence and brain deficits or impairment [93, 105]. In this study, we use a total, raw score. Finally, the Spatial Relations Test is available at T4-T5, which is derived from Thurstone's Primary Ability Test [6]. It is a distinct measure of intelligence and involves the mental manipulation of objects in space (see [69]). All of the measures used in the HHDP are coded such that higher scores indicate better cognitive performance, with the exception of the Halstead Subtests (Trail Making A and B and the Category test).

As can be seen in Table 1, in general, all of the maturation values (including the total maturation score) increase over time, as is expected. Interestingly, civic maturation dips around age 18 before increasing in later years. In addition, crime follows the classic age-crime curve pattern, peaking at time 3 .

\section{Analytic Strategy}

Our primary analyses utilize longitudinal growth curves to examine the ways in which maturation is related to crime and delinquency over time. We first conduct linear growth curve analyses with the maturation domains as the dependent variables to examine how they unfold over the life course. The primary analyses use binomial regression because the dependent variable is a variety score and does not meet the assumptions of linear or count-style models. The variety score can be thought of as representing nine Bernoulli "trials" in which an individual can have a success or failure. This approach follows that of Apel and Kaukinen [3], and the formula used in the main analyses is as follows:

$$
\operatorname{Pr}(Y=y \mid \pi)=\frac{n !}{y !(n-y) !} \pi^{y}(1-\pi)^{n-y}
$$




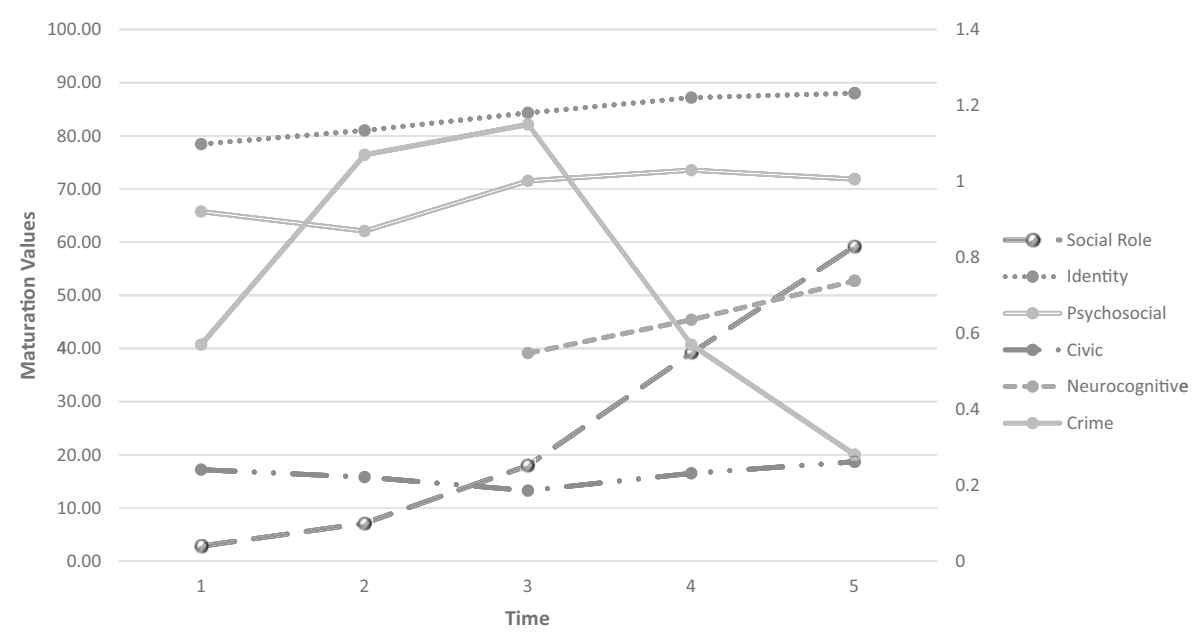

Fig 1 Maturation domains and crime over time

Here, $\pi$ indicates the probability of success on a trial (recall that we have nine crime types or trials) adjusting for the control variables [3, 103]. Our results are akin to estimating a logistic regression with nine trials and the coefficients can, like logistic regression coefficients, be translated to odds ratios by exponentiating them. ${ }^{6}$ Finally, we note that age is centered at the mean for the models examining crime and at age 12 for the maturation growth curves. ${ }^{7}$

\section{Results}

Figure 1 illustrates the growth in overall maturation as well as each domain. Juxtaposed against these graphs, we plot mean levels of delinquency as well in Fig. 1. The growth in delinquency/crime is also non-linear, following the classic age-crime curve.

Table 2 displays the results of growth curve models for each of the five domains of maturation as well as a total maturation domain, which is simply the average for each score across the five domains at each time period. With the exception of neurocognitive maturation, each domain is curvilinear in growth, indicating that there is a peak in maturation for most of the domains at which point growth levels out. It is not surprising that neurocognitive maturation did not have a significant age-squared term, since it is only measured at three time periods. The non-linearity of the maturation domains is somewhat unexpected but perhaps not surprising given the non-linearity of crime. It may be that maturation "peaks" after a rapid acceleration and then levels off in adulthood. $^{8}$

\footnotetext{
${ }^{6}$ In Stata, the command for this estimate is xtmelogit and the user specifies the number of trials as an option (e.g., $\operatorname{bin}(9))$.

${ }^{7}$ Following Nagin [61], we divide the centered age terms by 10 to aid in estimation.

${ }^{8}$ Note that we conducted likelihood ratio tests to determine whether random effects were warranted for age for each model. Where the results indicated they were not warranted, they were not included.
} 


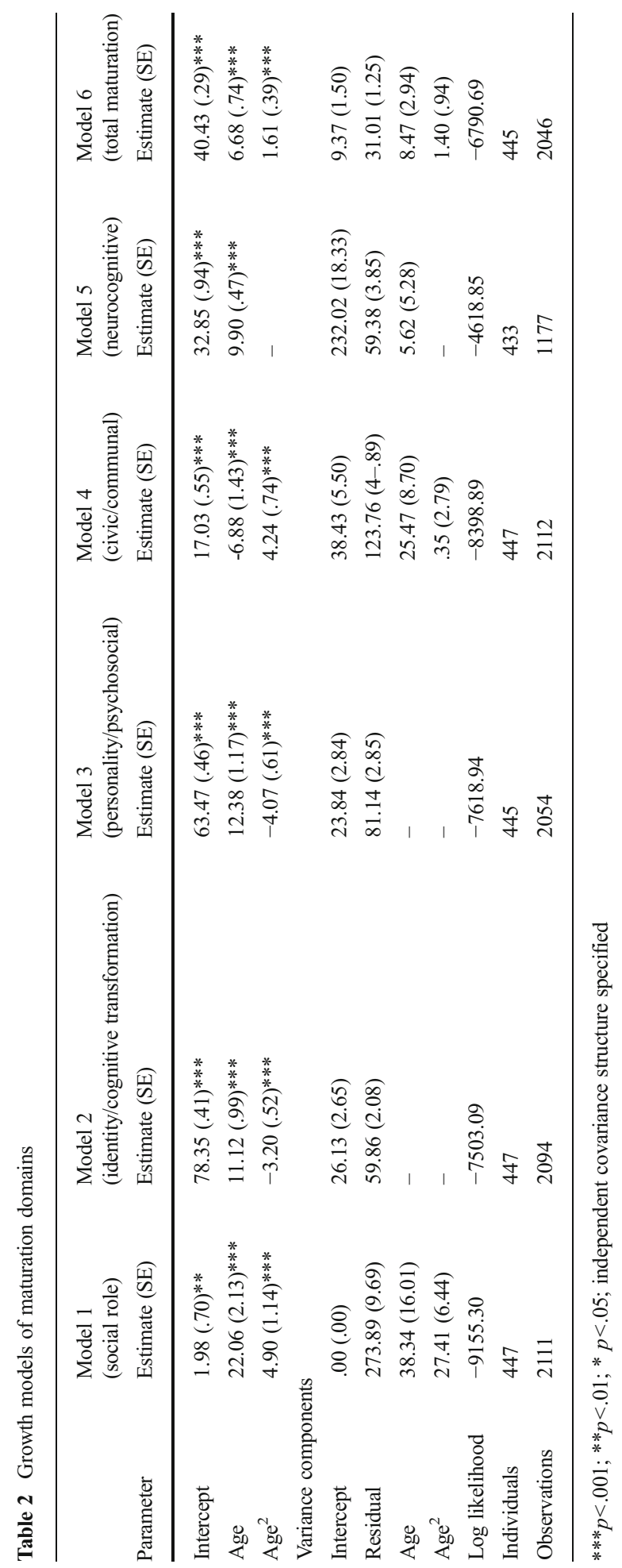




\section{Associations Between Maturation and Crime}

Table 3 displays bivariate correlations between each maturation domain and overall maturation and crime, using the person-period (e.g., time nested within individuals) dataset. Each domain is strongly and negatively related to crime over the life course. In addition, the overall maturation score is negatively and significantly related to crime. Interestingly, the total maturation score does not have the strongest correlation with crime. Identity/cognitive transformation maturation has the largest bivariate relationship with crime over the life course.

Table 4 displays the results of the growth curve analysis using multivariate binomial regression models. Maturation is shown in terms of an average, overall score (a between-individual effect) and in a time-varying (within-individual) manner. The time-varying score, which is calculated as a deviation from the within-group mean, is of most interest for our purposes. However, it is interesting to note that, overall, average levels of maturation vary substantially and are significantly related to crime. That is, whether one is more mature on average over his/her life course affects his/her level of crime. Nonetheless, what we are primarily interested in is whether changes in maturation over time predict changes in criminal behavior.

In terms of the control variables, which are generally similar across models, sex, friend's deviance, and parental attachment have significant relationships to crime, in the theoretically expected directions. Specifically, males, compared to females, those with greater, compared to fewer, deviant peers, and those with less, compared with more, attachment to parents report higher levels of crime. Minority racial status has a negative relationship with crime.

The overall average level of adult social role maturation (model 1) is marginally related to crime over time. However, the within-individual measure is not. That is, it does not appear that deviations in adult social roles from their person-specific mean have a large impact on crime over time within this sample. In terms of the other social domain, civic/citizenship maturation (model 4), the results indicate that it too has little relationship with crime over the life course, at least as measured in this study. It is possible that other measures of civic engagement, such as voting or serving on governmental bodies, may be more ideal indicators of this domain.

Turning to the psychological domains, Model 2 shows that identity or cognitive transformation has the largest effects of any domain on crime. The coefficients for the within- and between-individual measures translate to an odds ratio of .93 and .96 for the between- (average) and within-individual measures. In other words, controlling for

Table 3 Bivariate relationships between maturation domains and crime/delinquency

\begin{tabular}{lll}
\hline & Obs & Variety Score \\
\hline Adult social role & 2111 & $-.14 * * *$ \\
Identity/cognitive transformation & 2094 & $-.33^{* * *}$ \\
Psychosocial/personality & 2054 & $-.14^{* * *}$ \\
Civic/communal & 2111 & $-.06^{*}$ \\
Neurocognitive & 1176 & $-.14^{* * *}$ \\
Total maturation & 2046 & $-.25 * * *$ \\
\hline
\end{tabular}

$* * * p<.001 ; * * p<.01 ; * p<.05$ 


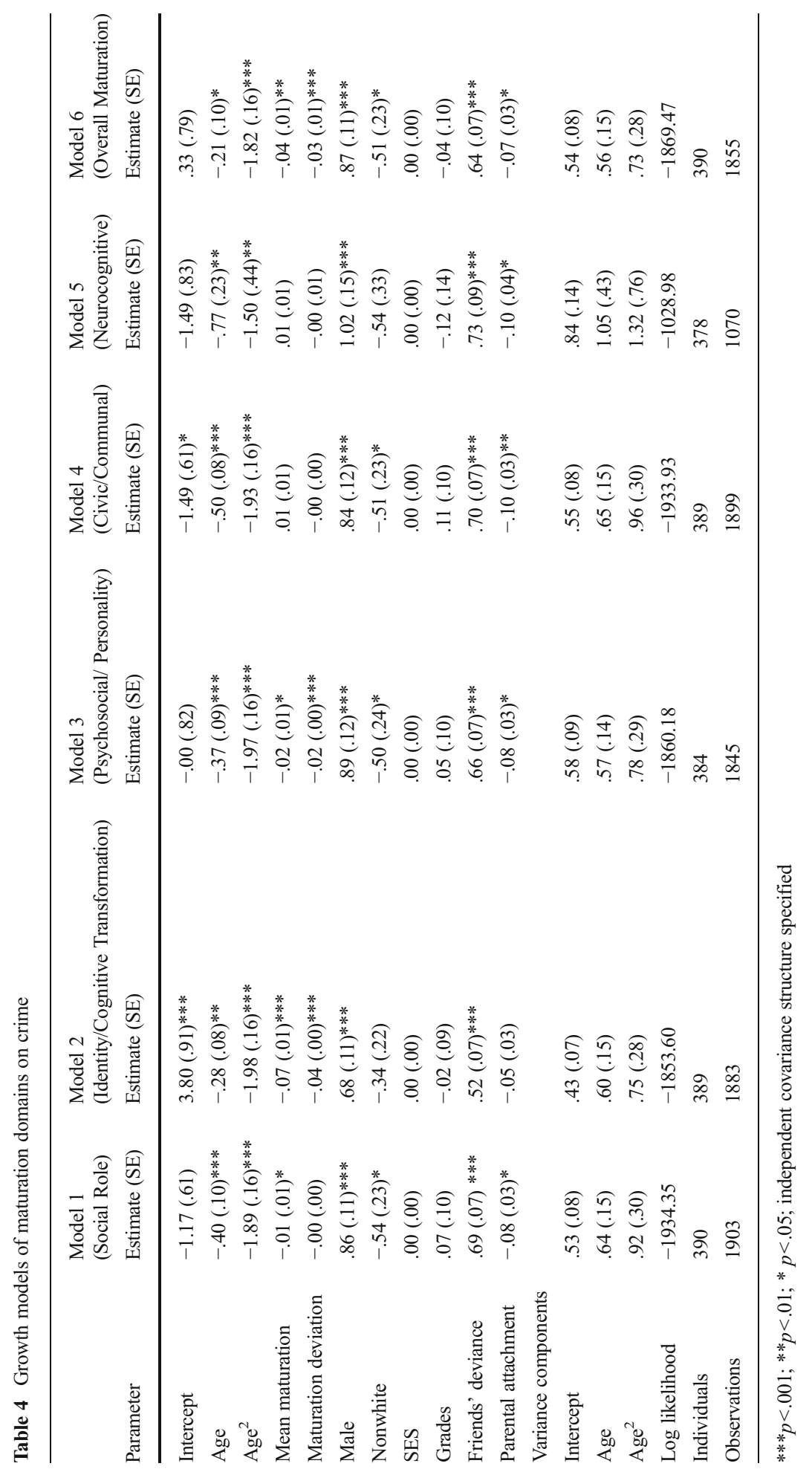


the covariates, a one unit increase in identity or cognitive transformation results in a 7 or $4 \%$ decrease in the odds of offending, respectively. It appears that identity has a particularly robust relationship with crime, as it also had the highest bivariate correlation with crime (even above the overall measure). Model 3 shows that psychosocial maturation, similar to identity, has both a between-individual and within-individual effect on crime. However, the within-individual effect appears to have a more substantial relationship with crime. These results indicate that increases in psychosocial maturation correspond to a reduction in criminal behavior. The effects are rather small, however, translating to an odds ratio of .98 for both the within- and between-individual level measures.

Neurocognitive maturation, much like civic maturation, does not appear to have a significant relationship with crime over time. Again, we note that these measures were only collected at three time points so our ability to detect changes over time is somewhat limited. This measure did have a significant bivariate relationship with crime.

Finally, Model 6 displays the results for the total maturation measure. Similar to the psychosocial and identity domains, total maturation has a significant betweenindividual and a significant within-individual effect on crime. The effects translate to an odds ratio of .96 and .97 . It thus appears that, taken as a whole, overall maturation may be a meaningful and important factor in explaining desistance from crime.

\section{Discussion and Conclusion}

The study of crime and deviance over the life course has produced important findings in the last 20-30 years. Among these include the link between life transitions, subjective changes, and desistance from crime. At this stage of life course criminology, a plethora of explanations have been proffered to understand why crime declines over time and some have pitted explanations against each other in a theoretical competition of sorts (see [31, 51, 53]). To this point, with few exceptions (see [22, 23]), researchers have not empirically explored integrated perspectives as a way to more comprehensively understand the process of desistance.

In this study, we drew on recent formulations that have attempted to bring together the desistance and life course literatures in a way that offers a holistic understanding of crime over time. The perspective of maturation suggests that what some have heretofore viewed as distinct areas of human development and behavior over the life course may represent components of what it means to be an adult in today's society (see [75, 79]). While our measures of maturation were admittedly exploratory and limited, we were able to examine five domains of maturation in relation to crime over the life course.

Consistent with our theoretical expectations, the results indicated that maturation generally increases from adolescence into young adulthood with the exception of the civic domain. Interestingly, only identity and neurocognitive maturation increased monotonically (though neurocognitive maturation was not significant in the growth models, perhaps because of only being present for three time periods). Psychosocial and civic maturation dipped a bit before increasing over time, which is the inverse trend for crime/delinquency. Also, consonant with theoretical expectations, all five of the 
domains as well as the overall measure of maturation were significantly and negatively correlated with crime over time.

The growth curve models revealed a more nuanced story, with three of the five domains and the overall measure showing a between- and/or within-individual relationship with crime. Civic and neurocognitive maturation had neither relationship, but we note that neurocognitive maturation only had three time points and thus growth curve model results should be interpreted with caution. Psychosocial, identity/cognitive transformation, and overall maturation showed relatively strong between- and withinindividual effects on crime.

These results indicate promise for the maturation perspective but also provide some reason for pause. It does appear that the social role, psychosocial, and identity/cognitive transformation domains represent perhaps useful indicators of the transition to adulthood and overall development that may be related to antisocial behavior. While our growth model findings with respect to adult social roles are not strong, the literature is generally consistent, finding that marriage, parenthood, and employment protect against crime [7, 45, 51, 81, 85]. Civic and neurocognitive maturation appear, from the literature at least, to be useful in terms of measuring maturation, but our measures were not supportive of their relationship to crime.

To the extent that maturation does have an effect on desistance from crime, the domains studied here should inform policy. Programs already in existence speak somewhat to elements of the domains most strongly related to crime (identity and psychosocial). For example, as mentioned earlier, self-control and impulsivity are key components of psychosocial maturation. In a recent Campbell Collaboration review of the literature, Piquero et al. [72] found that programs can increase selfcontrol thus reducing the probability of crime or antisocial behavior. While their study was limited to children, recent research has shown that self-control can be increased even into adulthood [63]. Thus, not only should psychosocial maturation be a target for offender rehabilitation, but also a target for crime prevention programs. Many child-centered programs target elements of psychosocial maturation as well, including conscientiousness and impulsivity (see [24, 95]). Certain well-validated prison programs also focus on "criminogenic needs," including antisocial attitudes and views of the self [1]. These programs may impact the identity/cognitive transformation domain, in ways that reduce the likelihood of recidivism. For example, effective programs often target antisocial attitudes [2, 46], which is a component of identity maturation, as defined in this study. Of all the domains, identity maturation was most consistently related to crime; thus, prevention and rehabilitation programs would be well-served to focus on instilling a conformist identity in individuals and the evidence bears this out. Ward and Marshall's (2004) "Good Lives Model" is one promising approach to offender rehabilitation that may be useful for improving prosocial identity (see [80] for more information on rehabilitation from a maturation viewpoint). In sum, a prosocial identity is an important element that prevention and rehabilitation efforts should take into account.

From a theoretical and empirical standpoint, the other maturation domains are linked to identity (all are correlated with identity maturation at the $p<.05$ level over time), which implies that a focus on increasing levels of other domains of maturation may also 
positively influence identity. For example, allowing ex-felons the right to vote may increase a sense of civic engagement and feelings of being a participatory citizen [96, 98]. This, in turn, may have a positive influence on how the individual views themselves. The same may be true for other domains, such as psychosocial maturation or social role maturation.

The finding that identity has a strong relationship with desistance should encourage researchers to further pursue more clear and direct measures of identity and identity change over time. Our main identity measure utilized a set of questions about how the individuals thought of themselves, and some of the items (e.g., I am a delinquent) may be redundant to a degree, with the dependent variable. More nuanced quantitative measures of identity seem warranted and may be a fruitful direction for future research. This research could be informed by more fully fleshed out theoretical descriptions of just how identity changes. Thus far, the qualitative literature is very clear that something about the identities of desisting.

Finally, our results show that maturation tends to continue or progress throughout adolescence and into the 20s. This belies the notion that age 18 is a magical marker for adulthood and makes the case for a more nuanced understanding of maturation. The measure of civic maturation in particular, seems to dip at age 18 , which may indicate that this period is characterized by many new developments occurring at once (graduation, legal voting age, military eligibility, etc.) that may require a period of adjustment before maturation (as we have defined it here) can continue to completion. ${ }^{9}$

This study is certainly not without limitations. As mentioned earlier, this represents a first step at measuring a theoretically promising avenue for understanding crime over the life course. Our measures are preliminary, particularly with respect to the civic and neurocognitive domains; it may, therefore, be a little wonder that these domains had the weakest relationship to crime. With respect to civic maturation, it would have been better to include more adult communal activities, such as voting or volunteering in community organizations. We also did not have an ideal measure of certain psychosocial maturation elements, particularly "perspective." ${ }^{10}$ We utilized a battery of items that represent the tendency to think about others and be helpful/understanding, which seems to be consistent with Cauffman and Steinberg's [12] formulation, but other measures may be better suited for this domain. Our neurocognitive domain also was limited in that it was not available at $\mathrm{T} 1$ or $\mathrm{T} 2$ and relied on tests rather than direct observation of brain structure and functioning. Future research should seek to measure these domains to better determine whether they are useful empirical maturation characteristics.

Even the other domains that had strong relationships with crime had measurement limitations. For example, the psychosocial domain incorporated factors that were not consistently available over time. We addressed this with measurement

\footnotetext{
${ }^{9}$ We would like to thank an anonymous reviewer for pointing out this possibility.

${ }^{10}$ We re-estimated the crime regression models using a measure of psychosocial maturation without "agreeableness," which may not be the most ideal proxy for perspective. The results were generally similar, with the between and within-individual coefficients both significant at $(p<.05)$. The psychosocial maturation score did decrease somewhat, however.
} 
approaches, which standardized each domain over time, but it may be preferable to have the same measures at each data collection point. We were somewhat surprised by the lack of robustness in the relationship between the adult social role maturation domain and crime given the substantial body of work that has demonstrated that relationships and work are related to desistance from crime (e.g., [81]). Ours is a community sample with theoretically less variation both in life transitions and crime than previous studies, which may help explain the discrepancy. In addition, minority status had a negative relationship with crime, likely because all nonwhites were grouped together (e.g., Asian and AfricanAmerican).

Aside from measurement, it may be the case that maturation includes more than the five domains examined in this study. The work drawn earlier [75, 79] sought a developmentally sound description of maturation that meshed with research in life course criminology. Other possibilities include biological indicators (such as puberty) that we did not included here, although some researchers have examined previously in relation to crime (see [5, 58]). However, it is arguable whether pubertal maturation is relevant for desistance, which typically occurs in the mid-20s (emerging adulthood). In addition, the domains identified here, while drawn from the criminological and life course literature, appear to be somewhat comprehensive, representing adult roles, emotional, psychological, and cognitive aspects of becoming an adult. Thus, the definition of maturation may be applicable to more than just examinations of crime over the life course. In fact, Rocque's [79] maturation perspective may be a more global measure of maturation, and it is possible that not all aspects of maturation are related to criminal behavior.

Finally, we should note that, while beyond the scope of this study, there are theoretical reasons to believe that the effects of maturation may vary by sex [37, 102]. In analyses (not shown), we found that there were differences in the effect of social role maturation, in which both the between and within-individual coefficients were significant $(p<.05)$ for females but not males. Interestingly, the civic maturation between individual coefficients were significant for males but not females, and the psychosocial between individual coefficients were significant for females but not males. Yet, coefficient comparison tests [68] revealed only a significant difference between males and females for the within-individual coefficient of adult social role maturation out of all the crime models. There were also differences in terms of the maturation growth models by sex. For example, males begin at a higher level of social role maturation but females have a faster rate of change. Interestingly, there was no effect of sex in the growth models of overall maturation. Clearly sex-based differences in maturation (as defined here) are worthy of future investigation.

In sum, both the definition and the measurement of maturation remain puzzles for future work to tease out. We argue that our measures are consistent with accounts thus far offered in the literature and show some promise in helping to empirically identify what maturation means and how it is related to desistance from crime. This study is a starting point for future research and we hope it sparks further explorations of the measurement of maturation and whether it is a useful explanation of desistance from crime. 


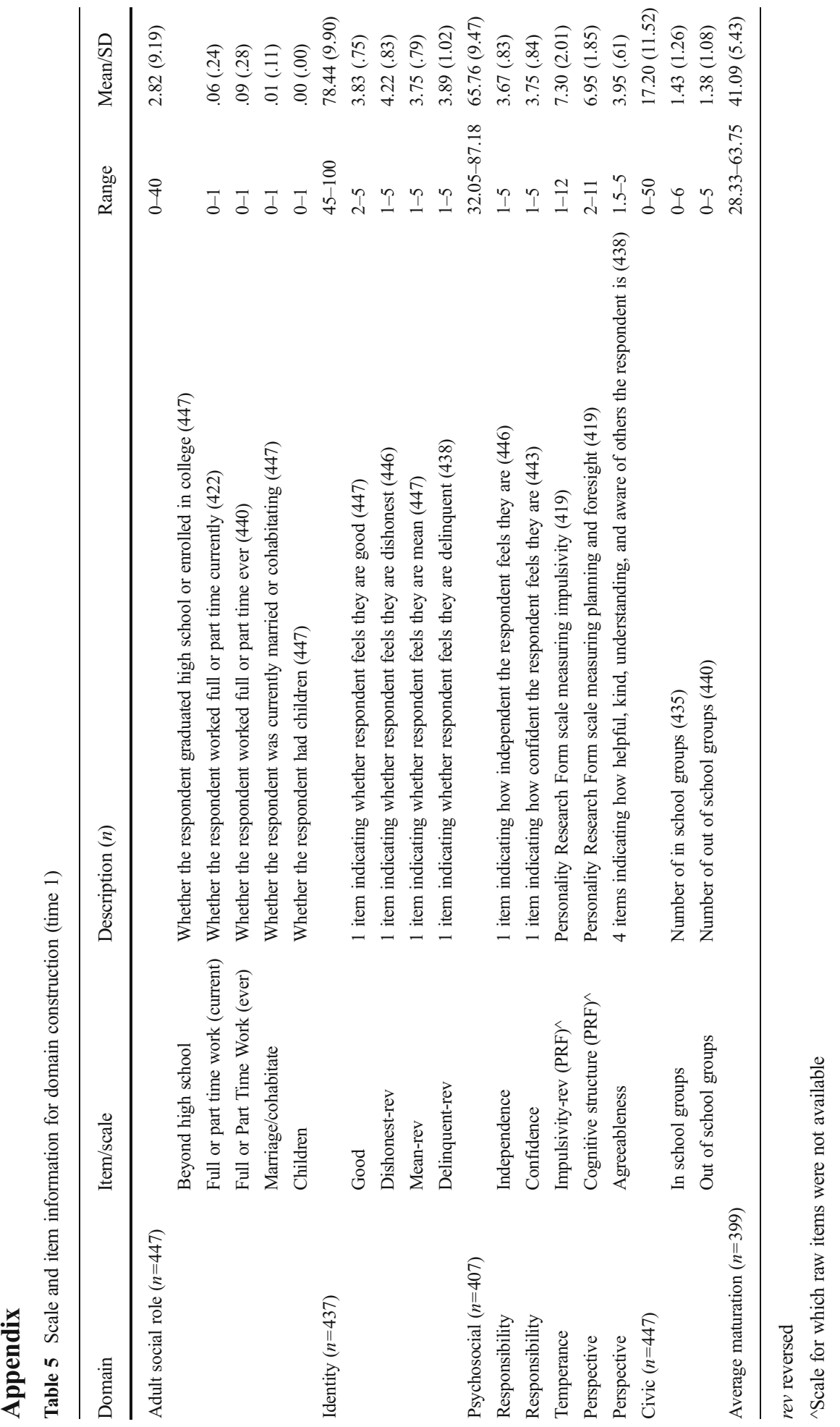




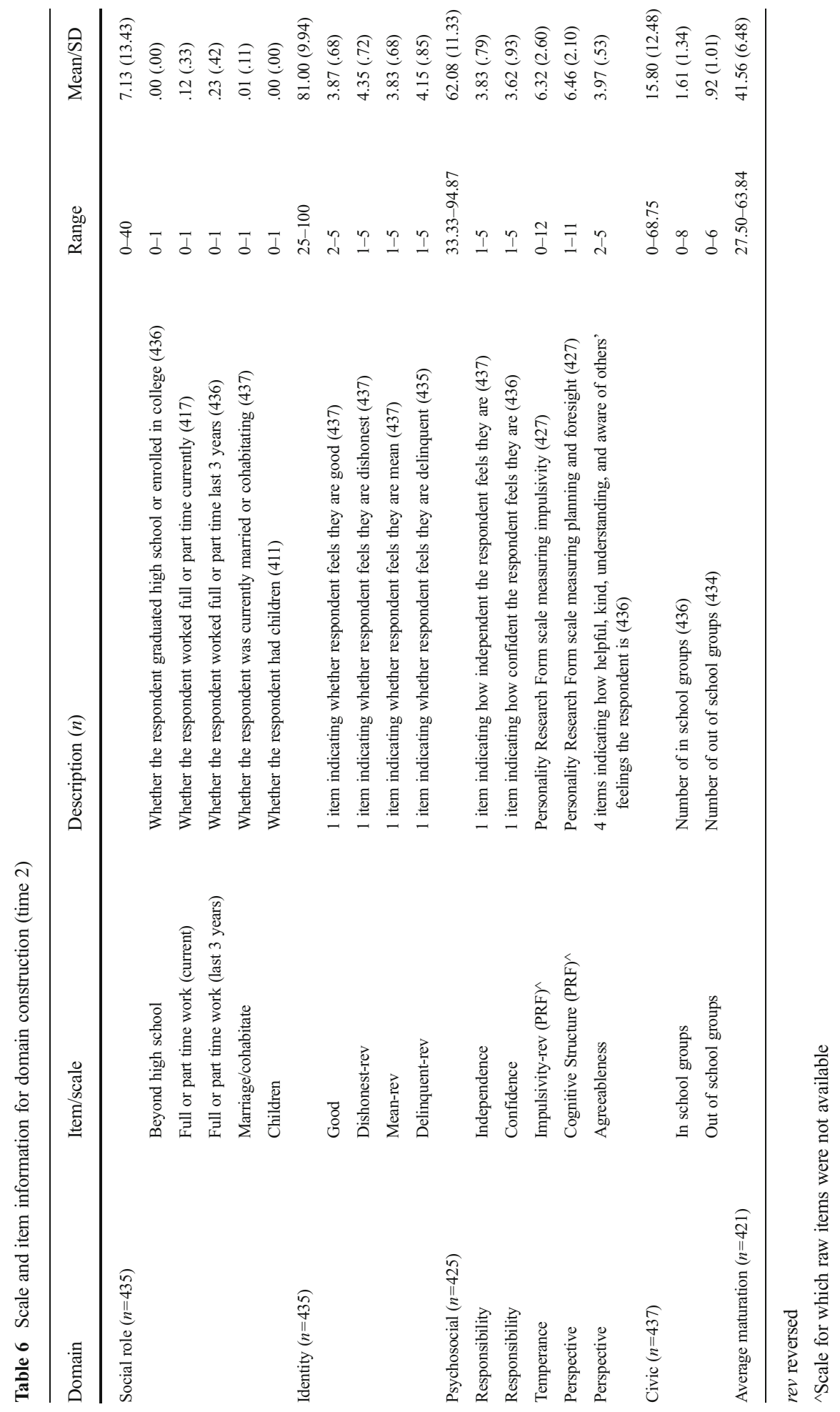




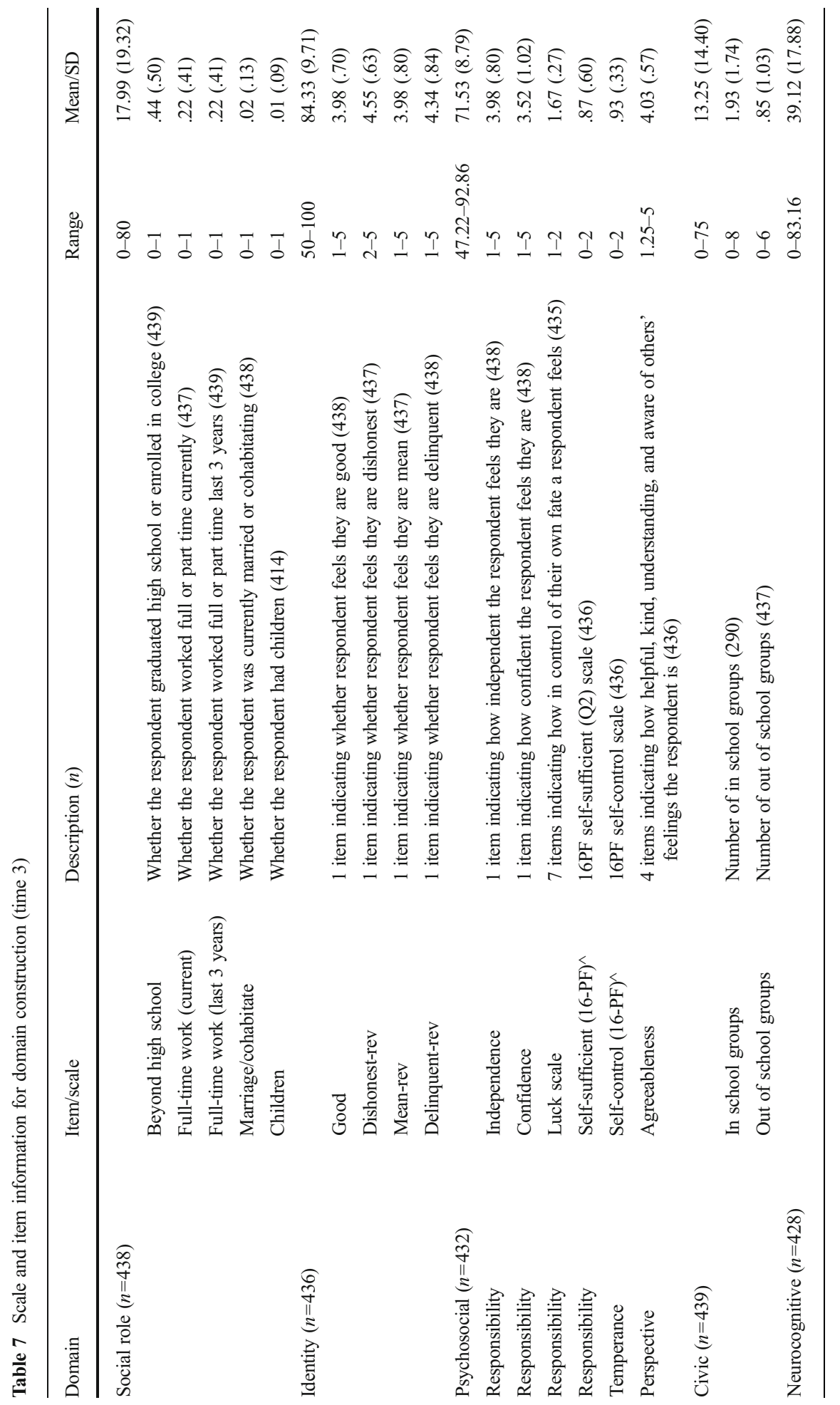




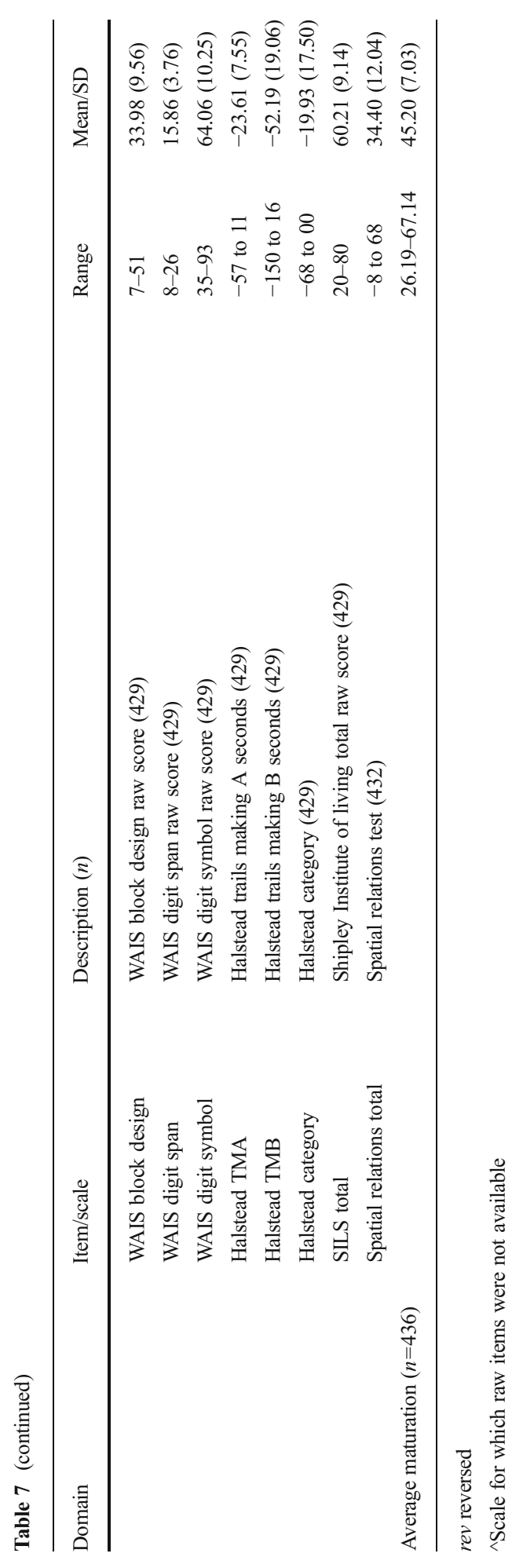




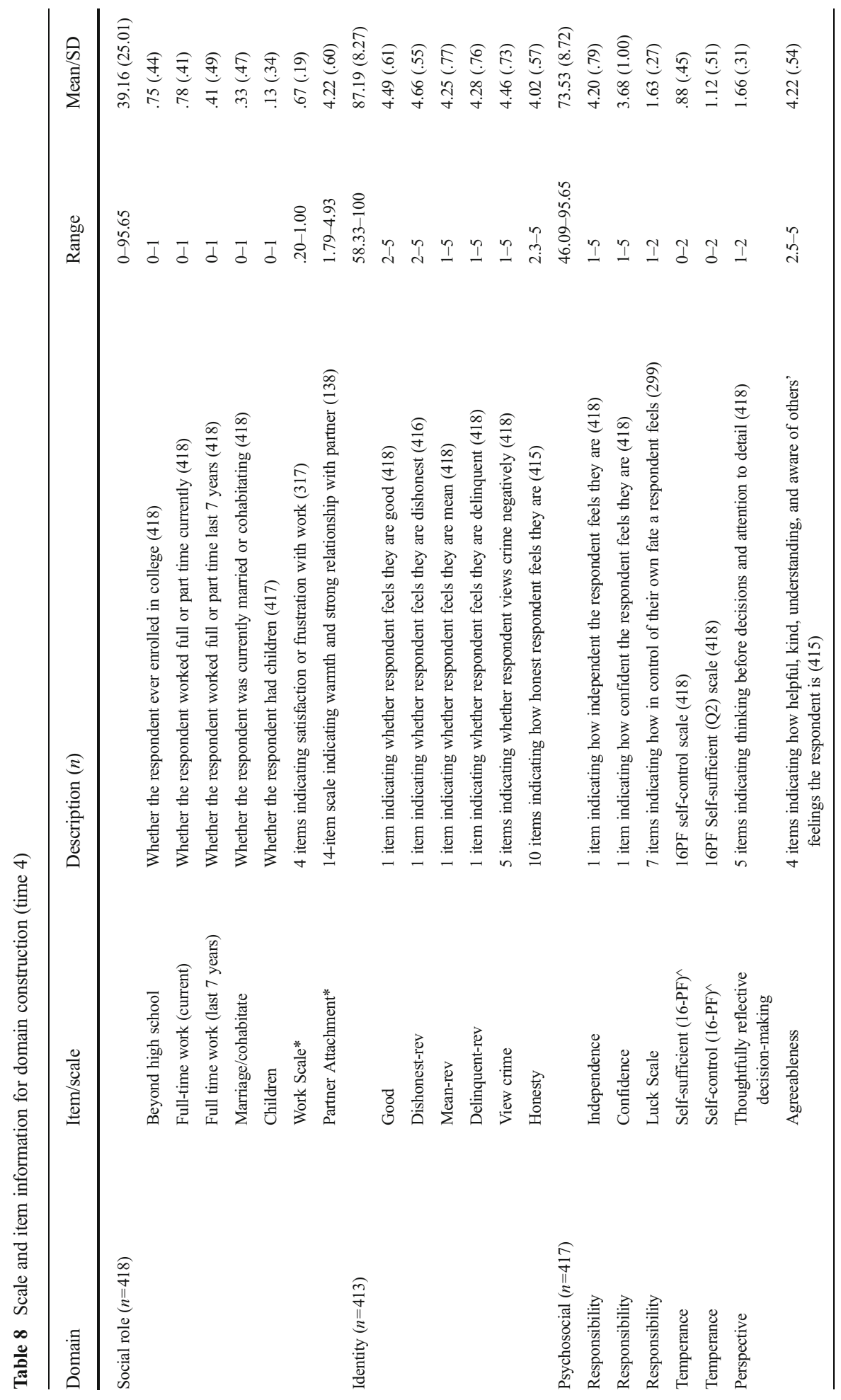




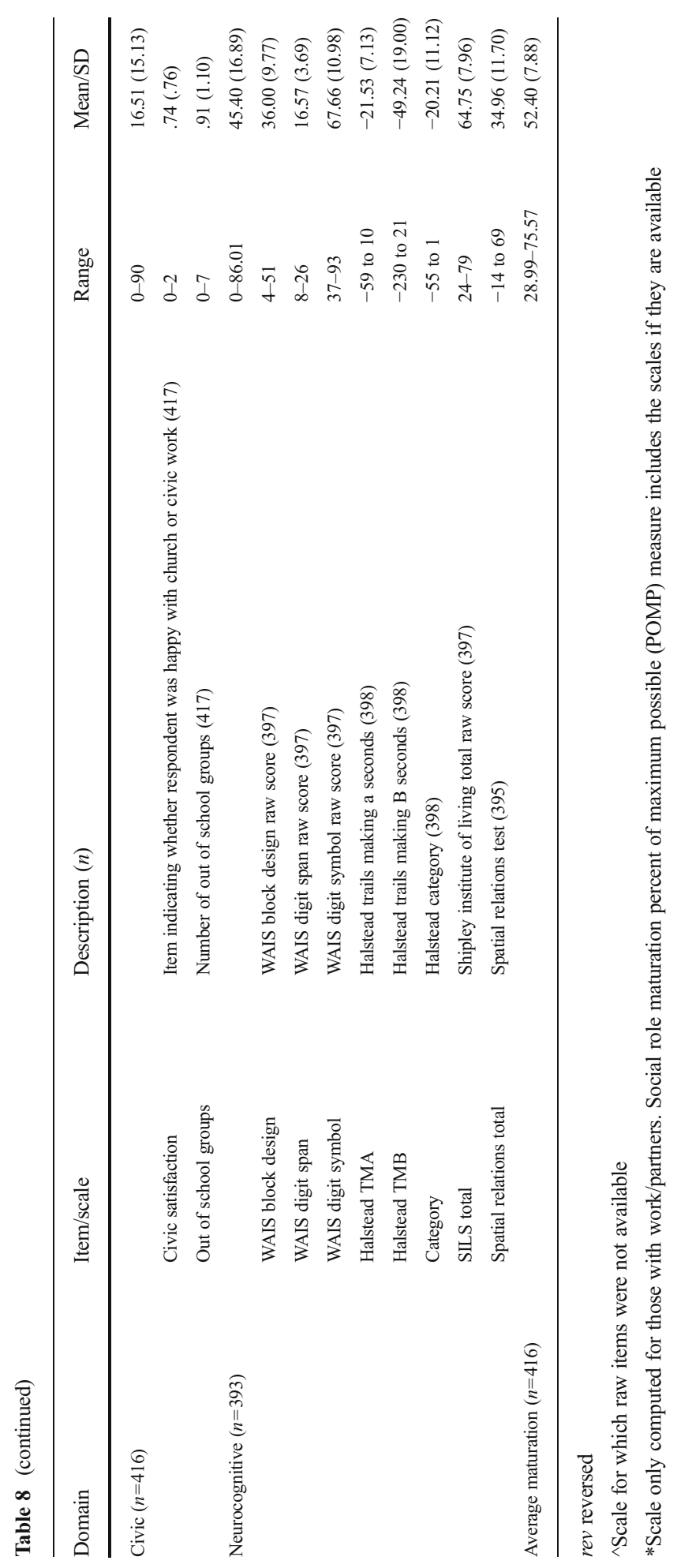




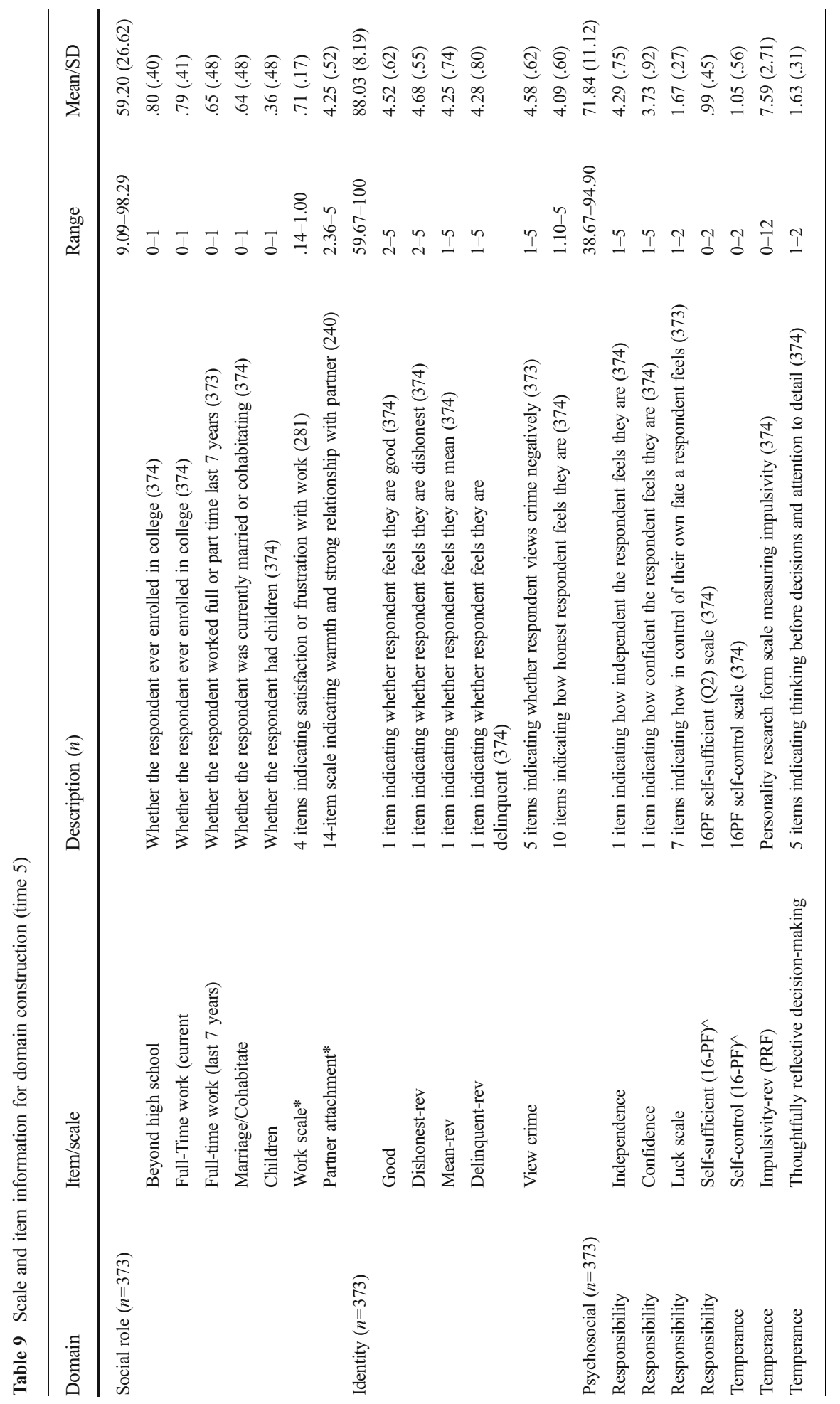




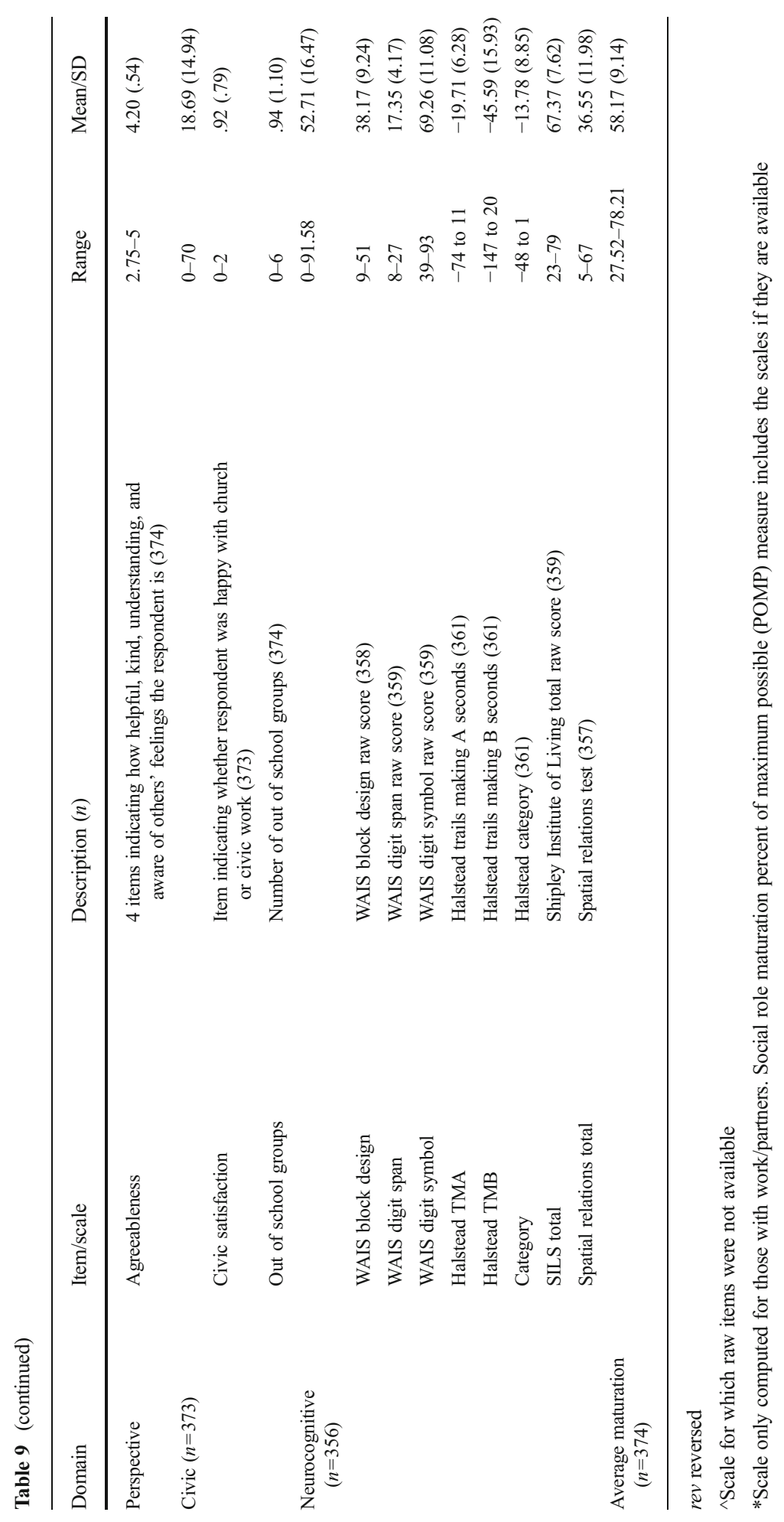


Acknowledgments The authors would like to thank Chet Britt, Ray Paternoster, and Ineke Marshall for their invaluable comments and advice on previous versions of this manuscript.

\section{Compliance with Ethical Standards}

Disclosures All subjects in this study provided assent with parents providing written consent until age 18; thereafter, the subjects provided written consent.

Conflicts of Interest The authors declare that they have no competing interests.

\section{References}

1. Andrews, D. A., \& Bonta, J. (2010). The psychology of criminal conduct. New Providence, NJ: LexisNexis Mathew Bender.

2. Andrews, D. A., Bonta, J., \& Wormith, J. S. (2006). The recent past and near future of risk and/or need assessment. Crime and Delinquency, 52(1), 7-27.

3. Apel, R., \& Kaukinen, C. (2008). On the relationship between family structure and antisocial behavior: parental cohabitation and blended households. Criminology, 46(1), 35-70.

4. Balsano, A. B. (2005). Youth civic engagement in the United States: understanding and addressing the impact of social impediments on positive youth and community development. Applied Developmental Science, 94(4), 188-201.

5. Barnes, J. C., \& Beaver, K. M. (2010). An empirical examination of adolescence-limited offending: a direct test of Moffitt's maturity gap thesis. Journal of Criminal Justice, 38(6), 1176-1185.

6. Bates, M. E., \& Tracy, J. I. (1990). Cognitive functioning in young social drinkers: is there impairment to detect? Journal of Abnormal Psychology, 99(3), 242-249.

7. Bersani, B. E., Laub, J. H., \& Nieuwbeerta, P. (2009). Marriage and desistance from crime in the Netherlands: do gender and socio-historical context matter? Journal of Quantitative Criminology, 25(3), $3-24$.

8. Blonigen, D. M. (2010). Explaining the relationship between age and crime: contributions from the developmental literature on personality. Clinical Psychology Review, 30(1), 89-100.

9. Blonigen, D. M., Hicks, B. M., Krueger, R. F., Patrick, C. J., \& Iacono, W. G. (2006). Continuity and change in psychopathic traits as measured via normal-range personality: a longitudinal-biometric study. Journal of Abnormal Psychology, 115(1), 85-95.

10. Bushway, S. D., \& Paternoster, R. (2014). Identity and desistance from crime. In J. A. Humphrey \& P. Cordella (Eds.), Effective interventions in the lives of criminal offenders (pp. 63-77). New York: Springer.

11. Cattell, H. E. P., \& Schuerger, J. M. (2003). Essentials of $16 P F$ assessment. Hoboken, NJ: Wiley.

12. Cauffman, E., \& Steinberg, L. (2000). (Im) maturity of judgment in adolescence: why adolescents may be less culpable than adults. Behavioral Sciences \& the Law, 18(6), 741-760.

13. Chassin, L., Dmitrieva, J., Modecki, K., Steinberg, L., Cauffman, E., Piquero, A. R., \& Losoya, S. H. (2010). Does adolescent alcohol and marijuana use predict suppressed growth in psychosocial maturity among male juvenile offenders? Psychology of Addictive Behaviors, 24(1), 48-60.

14. Cohen, P., Cohen, J., Aiken, L. S., \& West, S. G. (1999). The problem of units and the circumstance for pomp. Multivariate Behavioral Research, 34(3), 315-346.

15. Collins, R. E. (2004). Onset and desistance in criminal careers: neurobiology and the age-crime relationship. Journal of Offender Rehabilitation, 39(3), 1-19.

16. Craig, J., \& Foster, H. (2013). Desistance in the transition to adulthood: the roles of marriage, military, and gender. Deviant Behavior, 34(3), 208-223.

17. Diamantopoulos, A., \& Winklhofer, H. M. (2001). Index construction with formative indicators: an alternative to scale development. Journal of Marketing Research, 38(2), 269-277.

18. DeLisi, M., \& Piquero, A. R. (2011). New frontiers in criminal careers research, 2000-2011: a state of the art review. Journal of Criminal Justice, 39(4), 289-301.

19. Dmitrieva, J., Monahan, K. C., Cauffman, E., \& Steinberg, L. (2012). Arrested development: the effects of incarceration on the development of psychosocial maturity. Development and Psychopathology, 24(03), 1073-1090. 
20. Doherty, E. E., \& Ensminger, M. E. (2013). Marriage and offending among a cohort of disadvantaged African Americans. Journal of Research in Crime and Delinquency, 50(1), 104-131.

21. Duina, F. (2014). Life transitions in America. Malden, MA: Polity Press.

22. Farrall, S., \& Calverley, A. (2006). Understanding desistance from crime: theoretical directions in rehabilitation and resettlement. New York, NY: Open University Press.

23. Farrall, S., Sharpe, G., Hunter, B., \& Calverley, A. (2011). Theorizing structural and individual-level processes in desistance and persistence: outlining an integrated perspective. Australian and New Zealand Journal of Criminology, 44(2), 218-234.

24. Farrington, D. P., \& Welsh, B. C. (2007). Saving children from a life of crime: early risk factors and effective interventions. New York: Oxford University Press.

25. Flanagan, C., \& Levine, P. (2010). Civic engagement and the transition to adulthood. The Future of Children, 20(1), 159-179.

26. Fox, K. J. (2015). Theorizing community integration as desistance promotion. Criminal Justice and Behavior, 42(1), 92-94.

27. Forrest, W., \& Hay, C. (2011). Life-course transitions, self-control and desistance from crime. Criminology and Criminal Justice, 11(5), 487-513.

28. Forrest, W. (2014). Cohabitation, relationship quality, and desistance from crime. Journal of Marriage and Family, 76(3), 539-556.

29. Giedd, J. N., Blumenthal, J., Jeffries, N. O., Castellanos, F. X., Liu, H., Zijdenbos, A., \& Rapoport, J. L. (1999). Brain development during childhood and adolescence: a longitudinal MRI study. Nature Neuroscience, 2(10), 861-863.

30. Giordano, P. C., Schroeder, R. D., \& Cernkovich, S. A. (2007). Emotions and crime over the life course: a neo-Meadian perspective on criminal continuity and change. American Journal of Sociology, 112(6), 1603-1661.

31. Giordano, P. C., Cernkovich, S. A., \& Rudolph, J. L. (2002). Gender, crime, and desistance: toward a theory of cognitive transformation. American Journal of Sociology, 107(4), 990-1064.

32. Glueck, S., \& Glueck, E. T. 1937 (1966). Later criminal careers. New York: Krause Reprint Corp.

33. Glueck, S., \& Glueck, E. T. (1940). Juvenile delinquents grown up. New York: The Commonwealth Fund.

34. Glueck, S., \& Glueck, E. T. (1950). Unraveling juvenile delinquency. Cambridge, MA: The Commonwealth Fund.

35. Gogtay, N., Giedd, J. N., Lusk, L., Hayashi, K. M., Greenstein, D., Vaituzis, A. C., \& Thompson, P. M. (2004). Dynamic mapping of human cortical development during childhood through early adulthood. Proceedings of the National Academy of Sciences of the United States of America, 101(21), 8174-8179.

36. Gottfredson, M., \& Hirschi, T. (1990). A general theory of crime. Stanford, CA: Stanford University Press.

37. Graham, J., \& Bowling, B. (1995). Young people and crime. London: Home Office.

38. Gur, R. C. (2005). Brain maturation and its relevance to understanding criminal culpability of juveniles. Current Psychiatry Reports, 7, 292-296.

39. Hancock, Mary E. (1996). Prediction of problem behavior in adolescence: the impact of stability and change in the number of risk and protective factors. (Doctoral dissertation). Available from ProQuest Dissertations \& Theses database (UMI No. 9711059).

40. Helliwell, J. F. (2006). Well-being, social capital and public policy: what's new?*. The Economic Journal, 116(510), C34-C45.

41. Hirschi, T. (1969). Causes of delinquency. Berkeley, CA: University of California Press.

42. Hirschi, T., \& Gottfredson, M. R. (1983). Age and the explanation of crime. American Journal of Sociology, 89(3), 552-584.

43. Hirschi, T. (1989). Exploring alternatives to integrated theory. In S. F. Messner, M. D. Krohn, \& A. E. Liska (Eds.), Theoretical integration in the study of deviance and crime: problems and prospects (pp. 37-49). Albany, NY: SUNY Press.

44. Hollingshead, A. B. (1957). Two factor index of social position. New Haven, CT: Privately printed.

45. Horney, J., Osgood, D. W., \& Marshall, I. H. (1995). Criminal careers in the short-term: intra-individual variability in crime and its relation to local life circumstances. American Sociological Review, 60(5), 655-673.

46. Hubbard, D. J., \& Pealer, J. (2009). The importance of responsivity factors in predicting reductions in antisocial attitudes and cognitive distortions among adult male offenders. The Prison Journal, 89(1), 7998.

47. Jackson, D. N. (1974). Personality research form manual. Goshen, NY: Research Psychologists Press. 
48. Kaufman, A. S., \& Lichtenberger, E. O. (2006). Assessing adolescent and adult intelligence. Hoboken, NJ: Wiley.

49. King, S. (2013). Early desistance narratives: a qualitative analysis of probationers' transitions towards desistance. Punishment and Society, 15(2), 147-165.

50. Laub, J. H., \& Sampson, R. J. (2001). Understanding desistance from crime. In M. Tonry (Ed.), Crime and justice: a review of research (Vol. 28, pp. 1-69). Chicago: University of Chicago Press.

51. Laub, J. H., \& Sampson, R. J. (2003). Shared beginnings, divergent lives: delinquent boys to age 70. Cambridge, MA: Harvard University Press.

52. Laub, J. H., Nagin, D. S., \& Sampson, R. J. (1998). Trajectories of change in criminal offending: good marriages and the desistance process. American Sociological Review, 225-238.

53. LeBel, T. P., Burnett, R., Maruna, S., \& Bushway, S. (2008). The 'chicken and egg' of subjective and social factors in desistance from crime. European Journal of Criminology, 5(2), 131-159.

54. Leverso, J., Bielby, W., \& Hoelter, L. F. (2015). Back on the streets: maturation and risk factors for recidivism among serious juvenile offenders. Journal of Adolescence, 41(1), 67-75.

55. Manza, J., \& Uggen, C. (2004). Punishment and democracy: disenfranchisement of nonincarcerated felons in the United States. Perspectives on Politics, 2(03), 491-505.

56. Manza, J., \& Uggen, C. (2006). Locked out: Felon disenfranchisement and American democracy. New York: Oxford University Press.

57. Maruna, S. (2001). Making good: how ex-convicts reform and rebuild their lives. Washington, DC: American Psychological Association.

58. Moffitt, T. E. (1993). Adolescence-limited and life-course-persistent antisocial behavior: a developmental taxonomy. Psychological Review, 100(4), 674-701.

59. Monahan, K. C., Steinberg, L., Cauffman, E., \& Mulvey, E. P. (2009). Trajectories of antisocial behavior and psychosocial maturity from adolescence to young adulthood. Developmental Psychology, 45(6), 1654-1668.

60. Massoglia, M., \& Uggen, C. (2007). Subjective desistance and the transition to adulthood. Journal of Contemporary Criminal Justice, 23(1), 90-103.

61. Nagin, D. S. (2005). Group-based modeling of development. Cambridge, MA: Harvard University Press.

62. Paternoster, R., \& Pogarsky, G. (2009). Rational choice, agency and thoughtfully reflective decision making: the short and long-term consequences of making good choices. Journal of Quantitative Criminology, 25(2), 103-127.

63. Na, C., \& Paternoster, R. (2012). Can self-control change substantially over time? Rethinking the relationship between self-and social control. Criminology, 50(2), 427-462.

64. Opsal, T. (2012). 'Livin'on the straights': identity, desistance, and work among women post-incarceration. Sociological Inquiry, 82(3), 378-403.

65. O’Sullivan, K., Kemp, R., \& Bright, D. (2015). Identity, self-story and desistance from crime. Journal of Forensic Practice, 41, 67-75.

66. Pandina, R. J., Labouvie, E. W., \& White, H. R. (1984). Potential contributions of the life span developmental approach to the study of adolescent alcohol and drug use: the Rutgers health and human development project, a working model. Journal of Drug Issues, 14(2), 253-268.

67. Paternoster, R., \& Bushway, S. (2009). Desistance and the feared self: toward an identity theory of criminal desistance. Journal of Criminal Law and Criminology, 99(4), 1103-1156.

68. Paternoster, R., Brame, R., Mazerolle, P., \& Piquero, A. (1998). Using the correct statistical test for the equality of regression coefficients. Criminology, 36(4), 859.

69. Pellegrino, J. W., \& Hunt, E. B. (1991). Cognitive models for understanding and assessing spatial abilities. In H. A. H. Rowe (Ed.), Intelligence: reconceptualization and measurement. Hillsdale, NJ: Lawrence Erlbaum Publishers.

70. Piaget, J., \& Play, D. (1962). Please change citation to Piaget and Play. Imitation in Childhood. NY: Norton.

71. Piquero, A. R., Farrington, D. P., \& Blumstein, A. (2007). Key issues in criminal career research: new analyses of the Cambridge Study in Delinquent Development. Cambridge, UK: Cambridge University Press.

72. Piquero, A. R., Jennings, W. G., \& Farrington, D. P. (2010). On the malleability of self-control: theoretical and policy implications regarding a general theory of crime. Justice Quarterly, 27(6), 803834.

73. Piquero, A. R. (2013). Youth matters: the meaning of miller for theory, research, and policy regarding developmental/life-course criminology. New England Journal on Criminal and Civic Confinement, 39, $347-361$. 
74. Piquero, A. R. (2015). Understanding race/ethnicity differences in offending across the life course: gaps and opportunities. Journal of Developmental and Life-Course Criminology, 1(1), 21-32.

75. Prior, D., Farrow, K., Hughes, N., Kelly, G., Manders, G., White, S, \& Wilksinson, B. (2011). Maturity, young adults and criminal justice: a literature review. University of Birmingham, Institute of Applied Social Studies, School of Social Policy.

76. Putnam, R. D. (1995). Bowling alone: America's declining social capital. Journal of Democracy, 6(1), 65-78.

77. Quetelet, A. (1831/1984). Research on the propensity for crime at different ages. Translated and introduced by Sawyer F. Sylvester. Cincinnati: Anderson Publishing Company.

78. Rocque, M., Posick, P., \& Paternoster, R. (2014). Identities through time: an exploration of identity change as a cause of desistance. Justice Quarterly. Online First.

79. Rocque, M. (2015). The lost concept: The (re) emerging link between maturation and desistance from crime. Criminology and Criminal Justice., 15(3), 340-360.

80. Rocque, M., \& Welsh, B. C. (2014). Offender rehabilitation from a maturation/biosocial perspective. In M. Delisi \& M. G. Vaughn (Eds.), The Routledge international handbook of biosocial criminology (pp. 501-515). New York: Routledge.

81. Sampson, R. J., \& Laub, J. H. (1993). Crime in the making: pathways and turning points through life. Cambridge, MA: Harvard University Press.

82. Sampson, R. J., Laub, J. H., \& Wimer, C. (2006). Does marriage reduce crime? A counterfactual approach to within individual causal effects. Criminology, 44(3), 465-508.

83. Savolainen, J. (2009). Work, family and criminal desistance. British Journal of Criminology, 49(3), 285304.

84. Shover, N. (1996). Great pretenders: pursuits and careers of persistent thieves. Boston, MA: Northeastern University Press.

85. Siennick, S. E., \& Osgood, D. W. (2008). A review of research on the impact on crime of transitions to adult roles. In A. Liberman (Ed.), The long view of crime: a synthesis of longitudinal research (pp. 161187). New York: Springer.

86. Sowell, E. R., Thompson, P. M., Tessner, K. D., \& Toga, A. W. (2001). Mapping continued brain growth and gray matter density reduction in dorsal frontal cortex: inverse relationships during postadolescent brain maturation. The Journal of Neuroscience, 21(22), 8819-8829.

87. Spear, L. P. (2007). The developing brain and adolescent-typical behavior patterns: an evolutionary approach. In D. Romer \& E. F. Walker (Eds.), Adolescent psychopathology and the developing brain: integrating brain and prevention science (pp. 9-30). Oxford: Oxford University Press.

88. Spéder, Z., Murinkó, L., \& Settersten, R. A. (2014). Are conceptions of adulthood universal and unisex? Ages and social markers in 25 European countries. Social Forces, 92(3), 873-898.

89. Steffensmeier, D. J., Allan, E. A., Harer, M. D., \& Streifel, C. (1989). Age and the distribution of crime. American Journal of Sociology, 94(9), 803-831.

90. Steinberg, L., Cauffman, E., Woolard, J., Graham, S., \& Banich, M. (2009). Are adolescents less mature than adults?: minors' access to abortion, the juvenile death penalty, and the alleged APA "flip-flop". American Psychologist, 64(7), 583-594.

91. Steinberg, L. (2010). Commentary: a behavioral scientist looks at the science of adolescent brain development. Brain and Cognition, 72(1), 160-164.

92. Sweeten, G., Piquero, A. R., \& Steinberg, L. (2013). Age and the explanation of crime, revisited. Journal of Youth and Adolescence, 42(6), 921-938.

93. Szyhowski, D. (2008). A psychometric study of the Shipley Institute of Living Scale. (Doctoral Dissertation). Available from ProQuest Dissertations \& Theses database. (UMI No. 3317869).

94. Tombaugh, T. N. (2004). Trail making test A and B: normative data stratified by age and education. Archives of Clinical Neuropsychology, 19(2), 203-214.

95. Tremblay, R. E., \& Craig, W. M. (1995). Developmental crime prevention. In M. Tonry (Ed.), Crime and justice: a review of research (Vol. 19, pp. 151-236). Chicago: University of Chicago Press.

96. Uggen, C., \& Manza, J. (2004). Voting and subsequent crime and arrest: evidence from a community sample. Columbia Human Rights Law Review, 36, 193-216.

97. Uggen, C., \& Janikula, J. (1999). Volunteerism and arrest in the transition to adulthood. Social Forces, 78(1), 331-362.

98. Uggen, C., Manza, J., \& Behrens, A. (2004). Less than the average citizen: stigma, role transition, and the civic reintegration of convicted felons. In S. Maruna \& R. Immarigeon (Eds.), After crime and punishment: pathways to offender reintegration (pp. 258-290). Cullompton, Devon, UK: Willan.

99. Uggen, C., \& Manza, J. (2005). Disenfranchisement and the civic reintegration of convicted felons. In C. Mele \& T. A. Miller (Eds.), Civil penalties, social consequences (pp. 67-84). New York: Routledge. 
100. Walsh, A. (2009). Crazy by design: a biosocial approach to the age-crime curve. In A. Walsh \& K. M. Beaver (Eds.), Biosocial criminology: new directions in theory and research (pp. 154-175). New York: Routledge.

101. Ward, T., \& Marshall, W. L. (2004). Good lives, aetiology and the rehabilitiation of sex offenders: A bridging theory. Journal of Sexual Aggression: Special Issue: Treatment \& Treatability, 10(2), 153-169

102. Weaver, B., \& McNeill, F. (2015). Lifelines: desistance, social relations, and reciprocity. Criminal Justice and Behavior, 42(1), 95-107.

103. Weisberg, S. (2014). Applied linear regression. Hoboken, NJ: John Wiley \& Sons.

104. White, H. R., Pandina, R. J., \& LaGrange, R. L. (1987). Longitudinal predictors of serious substance use and delinquency. Criminology, 25(3), 715-740.

105. White, H. R., Bates, M. E., \& Buyske, S. (2001). Adolescence-limited versus persistent delinquency: extending Moffitt's hypothesis into adulthood. Journal of Abnormal Psychology, 110(4), 600-609.

106. Zoutewelle-Terovan, M., van der Geest, V., Liefbroer, A., \& Bijleveld, C. (2014). Criminality and family formation: effects of marriage and parenthood on criminal behavior for men and women. Crime and Delinquency, 60(8), 1209-1234. 